\title{
Article \\ Characteristics of Downward and Upward Longwave Radiation at Athalassa, an Inland Location of the Island of Cyprus
}

\author{
Stelios Pashiardis * and Soteris A. Kalogirou *,
}

check for updates

Citation: Pashiardis, S.; Kalogirou, S.A. Characteristics of Downward and Upward Longwave Radiation at Athalassa, an Inland Location of the Island of Cyprus. Appl. Sci. 2021, 11, 719. https://doi.org/10.3390/ app11020719

Received: 26 November 2020 Accepted: 7 January 2021

Published: 13 January 2021

Publisher's Note: MDPI stays neutral with regard to jurisdictional clai$\mathrm{ms}$ in published maps and institutional affiliations.

Copyright: (C) 2021 by the authors. Licensee MDPI, Basel, Switzerland. This article is an open access article distributed under the terms and conditions of the Creative Commons Attribution (CC BY) license (https:// creativecommons.org/licenses/by/ $4.0 /)$.
Department of Mechanical Engineering and Materials Science and Engineering, Cyprus University of Technology, P.O. Box 50329, 3603 Limassol, Cyprus

* Correspondence: spashiardis@cytanet.com.cy (S.P.); Soteris.kalogirou@cut.ac.cy (S.A.K.); Tel.: +357-2500-2621 (S.P. \& S.A.K.); Fax: +357-2500-2637 (S.P. \& S.A.K.)

+ Founding Member of the Cyprus Academy of Sciences, Letters, and Arts.

Abstract: In this study, two years of hourly longwave downward and upward irradiance measurements at Athalassa, an inland location, are used to analyze and compare them. A detailed quality control process was followed according to the suggested tests proposed by the Baseline Surface Radiation Network (BSRN) group. The criteria involved are based on physically possible, extremely rare and climatological limits. Furthermore, comparison tests were also applied between the two longwave components as well as with air and ground surface temperatures. Additionally, time consistency and persistency tests were applied. All the suspect data were excluded from the analysis. The data showed that the frequency distribution of downward longwave irradiances follows a normal distribution function, while the upward longwave follows an almost normal distribution but with a long positive tail. The annual mean daily downward longwave irradiation is $27.3 \mathrm{MJ} \mathrm{m}^{-2}$ and the annual mean daily upward longwave irradiation is $37.8 \mathrm{MJ} \mathrm{m}^{-2}$. The net longwave irradiation is always negative ranging from -5.9 to $-12.1 \mathrm{MJ} / \mathrm{m}^{2}$. Various models were tested to estimate daylight and all day downward and upward longwave irradiances under clear-sky and all-sky conditions. For the comparison of measured and estimated values the root-mean-square errors and linear regression correlations have been used. The results of this comparison showed that Idso's and Brunt's models perform well, and they can be used to estimate downward longwave irradiance under clear-sky conditions. Furthermore, both models were extended to estimate the daylight downward longwave irradiance under all-sky conditions by taking into account the ratio of global to the clear-sky global solar irradiance. In this case, the RMSE of the local calibrated coefficients scheme of Idso's model was $30.6 \mathrm{~W} \mathrm{~m}^{-2}$, while Brunt's model showed slightly lower value $\left(29.0 \mathrm{~W} \mathrm{~m}^{-2}\right)$.

Keywords: downward longwave radiation; upward longwave radiation; net longwave radiation; quality control; statistical analysis; modeling

\section{Introduction}

The radiation budget at the ground surface is important to understand the climate system and its variability. Net radiation $\left(R_{n}\right)$ is the sum of the net shortwave radiation $(0.3-$ $3.0 \mu \mathrm{m})\left(R_{n s}\right)$ and the net longwave radiation $(0.3-100 \mu \mathrm{m})\left(R_{n l}\right)$. The net shortwave is the difference between the incoming global solar radiation $(G)$ and the reflected radiation $(R)$ from the ground, while the net longwave radiation is the difference between the downward $\left(L_{d n}\right)$ and upward $\left(L_{u p}\right)$ radiation components. Therefore, the net radiation $\left(R_{n}\right)$ is generally defined as the difference between incoming and outgoing radiation of both short and long wavelengths and it is expressed as follows [1]:

$$
R_{n}=R_{n s}+R_{n l}=G\left(1-\rho_{g}\right)+L_{d n}-L_{u p}
$$


where $\rho_{g}$ is the surface albedo (fraction of Reflected radiation to Global radiation). Net radiation represents the effective energy provided by sun to heat soil and air as well as to evaporate soil surface water.

The downward longwave radiation originates from gases present in the atmosphere such as water vapor, carbon dioxide, and ozone. About $90 \%$ of the downward longwave radiation at the ground surface comes from the first 800-1600 $\mathrm{m}$ of the atmosphere [2]. Therefore, the water vapor pressure and the air temperature are closely related to $L_{d n}$. The role of clouds is also significant for the amount of the emitted downward irradiance [3,4]. On the other hand, the upward longwave radiation depends on the emittance/absorptance properties of the material at the ground surface and its temperature and is always higher than the downward irradiance. Therefore, the longwave radiation balance is normally negative. The knowledge of this radiation is important for agricultural meteorology and building heating/cooling systems, energy budget studies, frost forecasting and environmental applications [5-7]. Furthermore, the downward longwave radiation has shown a remarkable increase during the process of global warming [8].

The longwave radiation components can be estimated by four different methods [9], i.e., (1) direct measurements by pyrgeometers in meteorological stations, which is the most accurate method; (2) simple physical or empirical models which are the most popular and use mainly temperature and relative humidity and follow the Stefan-Boltzmann equation with recalibration of the coefficients under local conditions; (3) radiative transfer models which are data demanding and use meteorological observations from different layers of the atmosphere; and (4) through satellite observations where their accuracy needs to be improved. As outlined earlier, most of these empirical equations follow the Stefan-Boltzmann law:

$$
F=\varepsilon * \sigma * T_{s}^{4}
$$

where $F$ is the longwave radiation flux emitted by any surface which depends on the absolute surface temperature $T_{S}$ and on the longwave emittance $\varepsilon$. The constant $\sigma$ is the StefanBoltzmann constant $\left(\sigma=5.66697 * 10^{-8} \mathrm{Wm}^{-2} \mathrm{~K}^{-4}\right)$. The total emissivity can be estimated from clear-sky effective emissivity $\left(\varepsilon_{c}\right)$ and the emissivity which is modulated by clouds $\left(\varepsilon_{c l}\right)$. Dozens of parameterization formulas have been developed in which clear-sky effective emissivity is calculated as a function of the screen-level air temperature $\left(T_{a}\right)$ and water vapor pressure (e), since about half the longwave radiation comes from the lowest $100 \mathrm{~m}$ of the atmosphere [1]. Details about the formulae for estimating emissivity are given by various authors [10-12]. Prata [13] found that the precipitable water content was much better to represent the effective emissivity of the atmosphere than the water vapor pressure. Other authors [14,15] have extended the calculations of emissivity by adopting the effect of land use.

Alados-Arboledas [16] has estimated the effect of clouds on the longwave irradiance. The downward longwave radiation can be increased up to $34 \%$ with an overcast sky of low clouds [17]. Maghrabi et al. [18] have studied the influence of atmospheric water content, temperature, and aerosol optical depth on downward longwave radiation in arid conditions. Crawford and Duchon [12] proposed a cloud fraction for all-sky conditions, which was defined as the ratio of the measured solar radiation to the clear-sky radiation $\left(k_{c}\right)$. Other authors used the clearness index $\left(k_{t}\right)$, which is defined as the ratio of the measured solar radiation to the extraterrestrial solar radiation $[7,19]$. Therefore, the cloud modification factor ( $c l f^{\prime}$ or $c l f$ ) can be estimated as follows:

$$
c l f^{\prime}=1-k_{c} \text { or } c l f=1-k_{t}
$$

The determination of the daytime downward longwave radiation is estimated in all cases under clear-sky and all-sky conditions [4,11,20-23]. However, Chang and Zhang [7] have proposed a downward longwave model based on air temperature and relative humidity under all-sky conditions which are classified into four cases: All-day, nighttime, and daytime with and without considering the cloud modification factor. 
A lot of publications appeared in the literature concerning the shortwave radiation components measured at Athalassa [24-28], and Petrakis et al. [29] have presented the "Typical Meteorological Year" for Nicosia (Cyprus). More recently, Kalogirou et al. [30] presented an assessment of the solar radiation climate at two sites in Cyprus one at Athalassa an inland location and the second one at Larnaca a coastal location, based on measurements of about two years. Furthermore, Pashiardis et al. [31] have analyzed the direct, diffuse, and global short-wave irradiation using three years of data. The characteristics of the longwave downward and upward irradiance at two sites in Cyprus were also presented by Pashiardis et al. [9]. The paper has also evaluated various empirical models under clear-sky and all-sky conditions.

The current study covers two years of measurements (2016-2017) of various short and longwave radiation components and has four objectives. Firstly, the longwave data were undergone an extensive quality control process based on tests proposed by the Baseline Surface Radiation Network (BSRN). The tests include globally physical possible, extremely rare and climatological configurable limits as well as global cross-comparisons for the surface longwave radiation measurements [32]. Furthermore, consistency and persistency tests were applied to improve the validity of the data. Secondly, the data were statistically analyzed to reveal the characteristics of longwave radiation on a monthly and hourly basis. Furthermore, we implement simple empirical models which were developed in a previous study under clear and all-sky conditions using local calibrated coefficients [9]. Finally, the net longwave radiation is calculated from the difference of downward and upward longwave irradiances and estimated from other models based on air temperature, relative humidity and global solar radiation.

\section{Measurements and Quality Control Processes}

The radiation data on which this study is based are obtained from Athalassa meteorological station which is an inland plain location (Figure 1). The coordinates of the station are shown in Table 1.

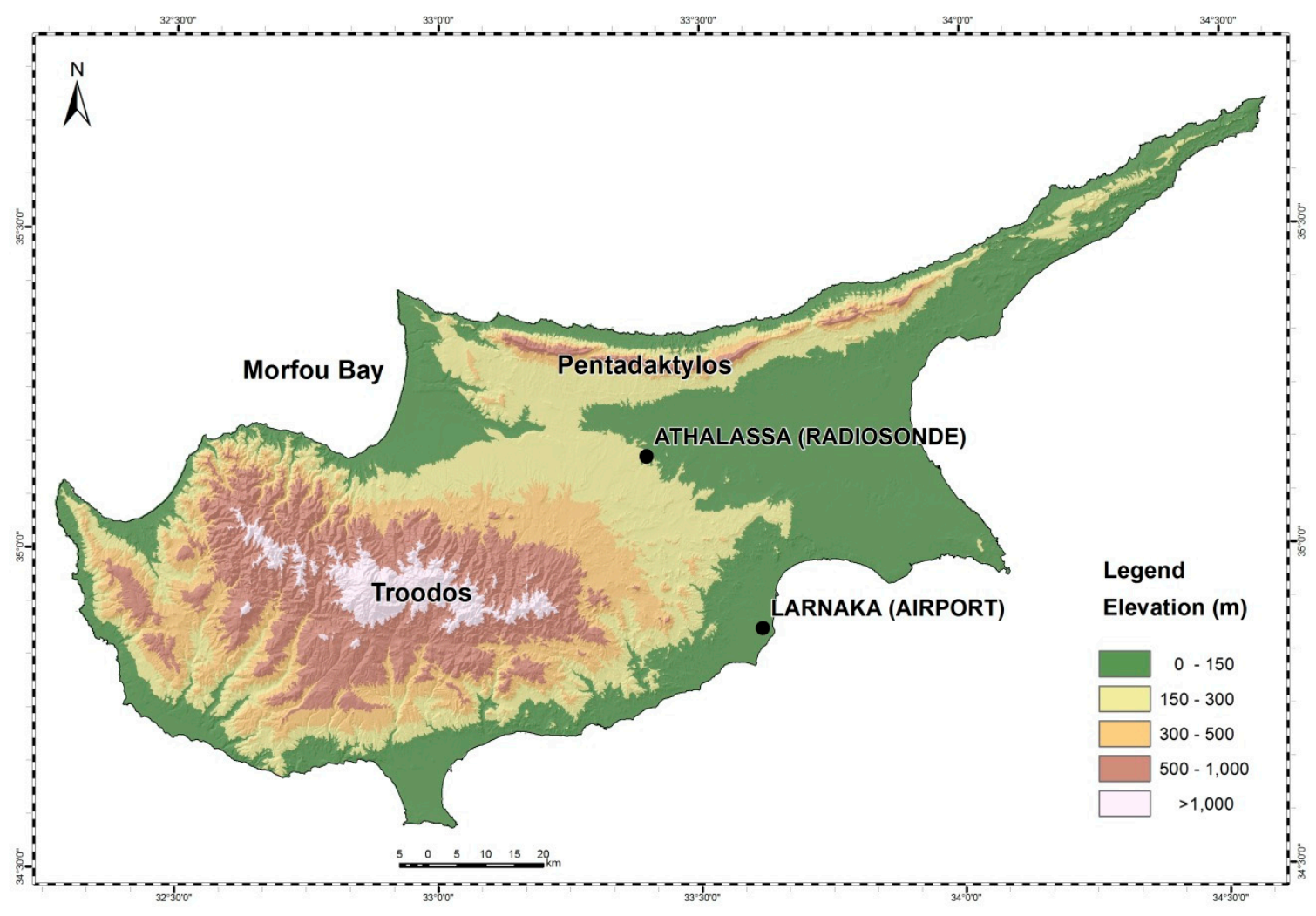

Figure 1. Map of Cyprus showing the location of Athalassa radiometric station. 
Table 1. Site parameters for the Athalassa meteorological station.

\begin{tabular}{ccccc}
\hline Site & Location & Latitude & Longitude & Altitude (m, m.s.l) \\
\hline Athalassa & Inland & $35.141^{\circ} \mathrm{N}$ & $33.396^{\circ} \mathrm{E}$ & 165 \\
\hline
\end{tabular}

The climate of Athalassa is typical Mediterranean with mild winters (mean seasonal air temperature of about $10.5^{\circ} \mathrm{C}$ ) and warm and dry summers (mean seasonal air temperature of about $29.5^{\circ} \mathrm{C}$ ). The annual rainfall is about $320 \mathrm{~mm}$. Rainfall is recorded mainly between October and March. The average annual sunshine duration is $3332 \mathrm{~h}$. The annual average daily global radiation is $18.5 \mathrm{MJ} \mathrm{m}^{-2}$ and the average yearly cumulative global irradiation is about $6763 \mathrm{MJ} \mathrm{m}^{-2}$. Statistical analysis showed that clear and partially cloudy days exceed the value of $80 \%$ of the year [30].

CG1 pyrgeometers obtained from Kipp and Zonen were used to measure the longwave radiation. All the sensors are factory calibrated, in accordance with the World Radiometric Reference (WRR) [33]. About 9\% of the upward longwave irradiance data values are missing, while the percentage of the downward longwave irradiance which is missing is about $25 \%$. The missing data are caused either from problematic functioning of the CG1 pyrgeometers or from problems related to the data logger system. Long missing data for both longwave irradiances are observed in the year 2017. Details about the quality control procedures for the shortwave solar radiation measurements can be found in [34].

\section{Longwave Radiation Quality Control}

The process of quality control for the longwave radiation is based on range tests which were suggested by the Baseline Surface Radiation Network (BSRN) group. BSRN has proposed globally physical possible, extremely rare, and climatological configurable limits as well as global cross-comparisons for the surface longwave radiation measurements [32] (Table 2).

Table 2. Physically possible and extremely rare global limits recommended by BSRN and user configurable climatological limits, as well as global cross-comparisons based on air temperature ( $\left.T_{a}\right)$ (in Kelvin) and between the two longwave variables. $\sigma$ is the Stefan-Boltzman constant $=5.67 \times 10^{-8} \mathrm{Wm}^{-2} \mathrm{~K}^{-4}$.

\begin{tabular}{|c|c|c|c|c|c|}
\hline & & & & \multicolumn{2}{|c|}{ Ranges } \\
\hline Test & \multicolumn{2}{|l|}{ Limits } & & $L_{d n}\left(\mathrm{~W} / \mathrm{m}^{2}\right)$ & $L_{u p}\left(\mathrm{~W} / \mathrm{m}^{2}\right)$ \\
\hline \multirow{2}{*}{ PPL } & \multirow{2}{*}{ Physically Possible Limits } & & Min & 40 & 40 \\
\hline & & & Max & 700 & 900 \\
\hline \multirow{2}{*}{ ERL } & \multirow{2}{*}{ Extremely Rare Limits } & & Min & 60 & 60 \\
\hline & & & Max & 500 & 700 \\
\hline \multirow{4}{*}{ CCL } & \multirow{4}{*}{ Climatological Configurable Limits } & \multirow{2}{*}{ 1st Level } & Min & 190 & 240 \\
\hline & & & Max & 465 & 590 \\
\hline & & \multirow{2}{*}{ 2nd Level } & Min & 145 & 210 \\
\hline & & & Max & 500 & 630 \\
\hline \multirow{4}{*}{ GCC } & \multirow{2}{*}{ Global Cross-Comparisons vs. $T_{a}$} & & Min & $0.4^{*} \sigma^{*} T_{a}^{4}$ & $\sigma^{*}\left(T_{a}-15\right)^{4}$ \\
\hline & & & Max & $\sigma^{*} T_{a}^{4}+25$ & $\sigma^{*}\left(T_{a}+25\right)^{4}$ \\
\hline & \multirow[t]{2}{*}{$L_{d n}$ vs. $L_{u p}$} & & $L_{d n}<L_{u p}+25 \mathrm{~W} / \mathrm{m}^{2}$ & & \\
\hline & & & $\mathrm{Min}=-300 \mathrm{~W} / \mathrm{m}^{2}$ & & \\
\hline$R_{n l}$ & Net Long wave irradiance & & $\operatorname{Max}=+25 \mathrm{~W} / \mathrm{m}^{2}$ & & \\
\hline
\end{tabular}

The "physically possible" tests detect extremely large errors in the radiation data. The radiation data falling in the intervals defined by the range between 40 and $700 \mathrm{~W} / \mathrm{m}^{2}$ for downward longwave irradiance and between 40 and $900 \mathrm{~W} / \mathrm{m}^{2}$ for the upward longwave irradiance are considered "physically possible". The data set passed the suggested physical limits.

The "extremely rare" limits are narrower than those of the "physically possible" limits, since they usually occur over very short time periods under very extreme conditions. 
Therefore, "good quality" is assumed to be inside the "extremely rare" limits. Figure 2 shows that downward longwave irradiances $\left(L_{d n}\right)$ are within the specified limits. However, about $0.4 \%$ of data of the upward longwave irradiances $\left(L_{u p}\right)$ have values slightly above $700 \mathrm{~W} / \mathrm{m}^{2}$, with a maximum value of $738 \mathrm{~W} / \mathrm{m}^{2}$ (Figure 2).

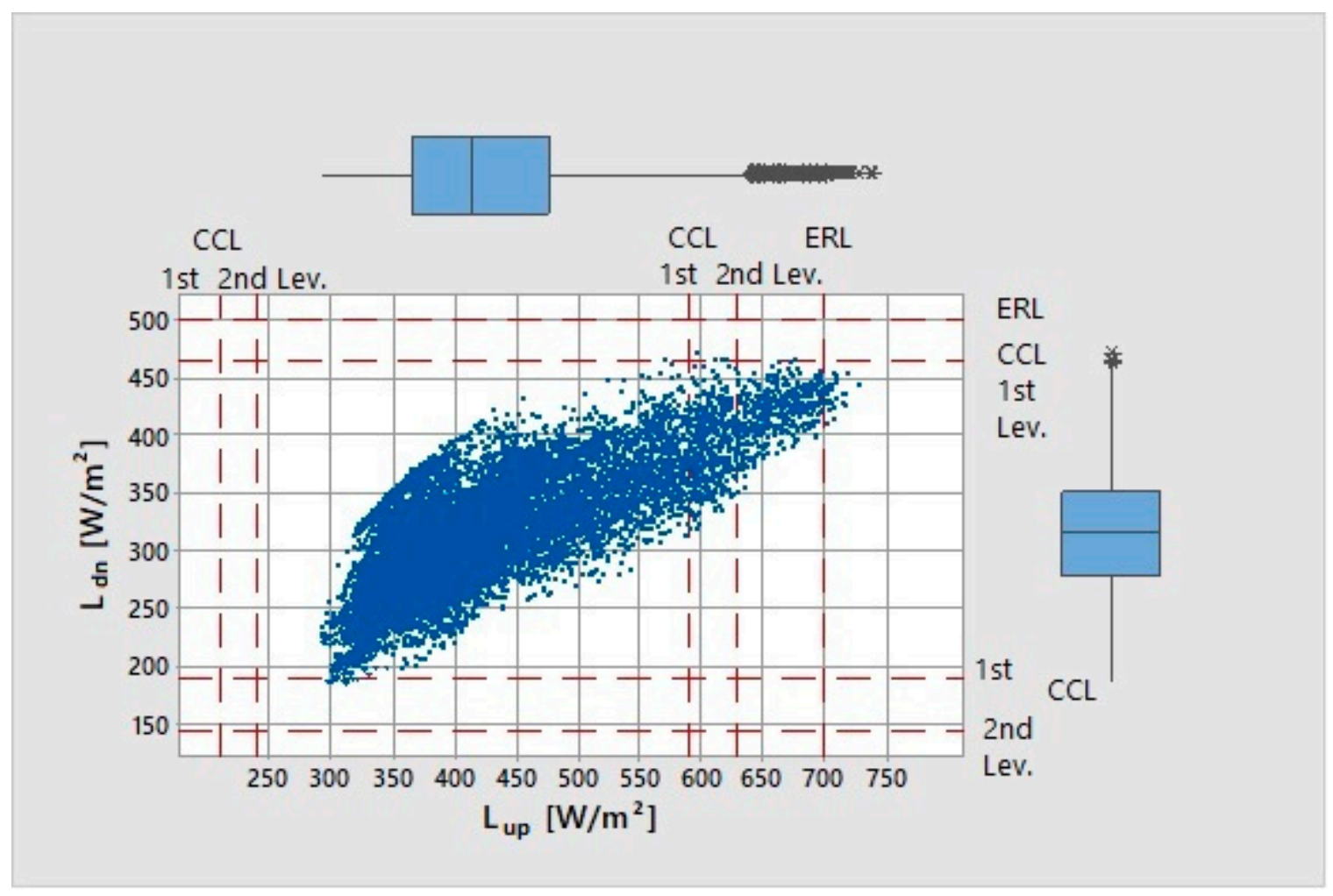

Figure 2. Marginal plot of the hourly downward and upward longwave irradiances at Athalassa. The scatter plot also shows the boxplots of the two variables. Reference lines are the extremely rare and the climatological limits (1st and 2nd level) for the upward and downward longwave irradiances as given by Table 2.

The suggested climatological limits are based on data obtained from the Great Plains in the United States. The limits are classified in two levels. The 1st level has the "smallest" testing limits, while those referred as "2nd level" give the second lower limits. Downward longwave irradiances passed all the given criteria, while the upward longwave irradiances showed slightly higher values than the suggested upper limits (Table 2). It has to be noted that some of the downward longwave values are as high as the outgoing longwave radiation. These values may be attributed to high aerosol optical depth values from warm layers above the planetary boundary layer [18].

The global cross comparison tests are referred to various comparisons between the two longwave irradiances and their relationships with air temperature data $\left(T_{a}\right)$ at the screen level. The formulae involved with temperature relationships have the following ranges:

$$
\begin{gathered}
0.4 * \sigma * T_{a}^{4}<L_{d n}<\sigma * T_{a}^{4}+25 \mathrm{~W} \mathrm{~m}^{-2} \\
\sigma *\left(T_{a}-15 K\right)^{4}<L_{u p}<\sigma *\left(T_{a}+25 K\right)^{4}
\end{gathered}
$$

The lower limit of the comparison test of Equation (4) is formulated in such a way that the value of the effective atmospheric emittance, defined by $\varepsilon_{a}=L_{d n} / \sigma * T_{a}^{4}$ is not possible to be less than 0.4 . On the other hand, a longwave component greater than a black-body emission at surface temperature, is also considered impossible. The comparisons between the two longwave components are also shown in Table 2. 
The results of these comparisons are shown in Figure 2. The marginal plot shows also the variability of the two variables through their boxplots. The boxplot of the downward irradiance is almost symmetrical around the mean value indicating that this variable follows an approximately normal frequency distribution function. On the other hand, the boxplot of the upward longwave irradiance shows a large number of outliers towards the upper tail of the boxplot. As indicated earlier, a small number $(0.4 \%)$ of the data points of the upward longwave irradiance are above the extremely rare limits $\left(700 \mathrm{~W} \mathrm{~m}^{-2}\right)$. However, it has to be noted that the climatological limits are based on observations measured in the Great Plains of United States, where the climatological conditions may be different from those in Athalassa. Furthermore, it has to be noted that air temperatures have increased by more than $0.5^{\circ} \mathrm{C}$ per decade in the recent years since 1980 due to the climate change process in the region of Eastern Mediterranean and Middle East [35-37]. Therefore, it is expected that both longwave components will have higher values in the future.

The effect of air temperature at the screen level on both longwave irradiances is illustrated in Figure 3. For example, for a range of air temperatures between 15 and $20^{\circ} \mathrm{C}$, the upward longwave irradiance is around $400 \mathrm{~W} / \mathrm{m}^{2}$, while the downward longwave irradiance ranges mainly between 250 and $350 \mathrm{~W} / \mathrm{m}^{2}$. Generally, $L_{d n}$ ranges between 200 and $450 \mathrm{~W} / \mathrm{m}^{2}$ during the day, while during the night when temperatures are lower, $L_{d n}$ has slightly narrower upper limits $\left(200\right.$ to $\left.400 \mathrm{~W} / \mathrm{m}^{2}\right)$. On the other hand, $L_{u p}$ ranges mainly between 300 to $700 \mathrm{~W} / \mathrm{m}^{2}$ during the day, while during the night it has also narrower upper limits ( 300 to $550 \mathrm{~W} / \mathrm{m}^{2}$ ).

As shown in Figure 4 the longwave data points, estimated by Equations (4) and (5) are within the ranges as described by the said equations. However, the downward irradiance at Athalassa during the period May-November 2017, showed unreasonable very low values and they did not pass the said criteria. Therefore, 4128 hourly values were excluded from the statistical analysis due to instability of the pyrgeometer. The total number of missing records for upward irradiances is only 1421 as shown by Table 3 .

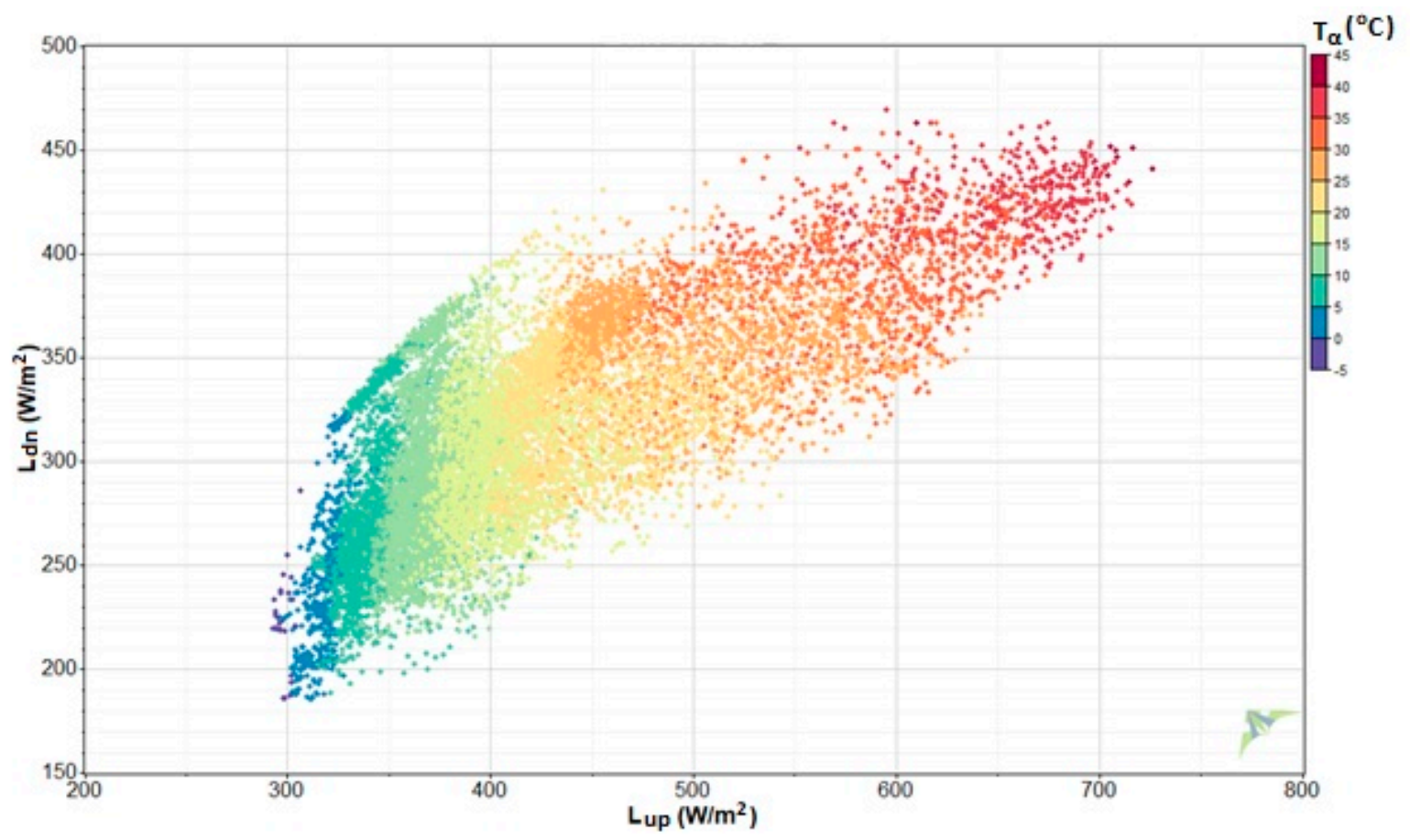

Figure 3. The effect of air temperature at the screen level on both the downward and upward longwave irradiances. 

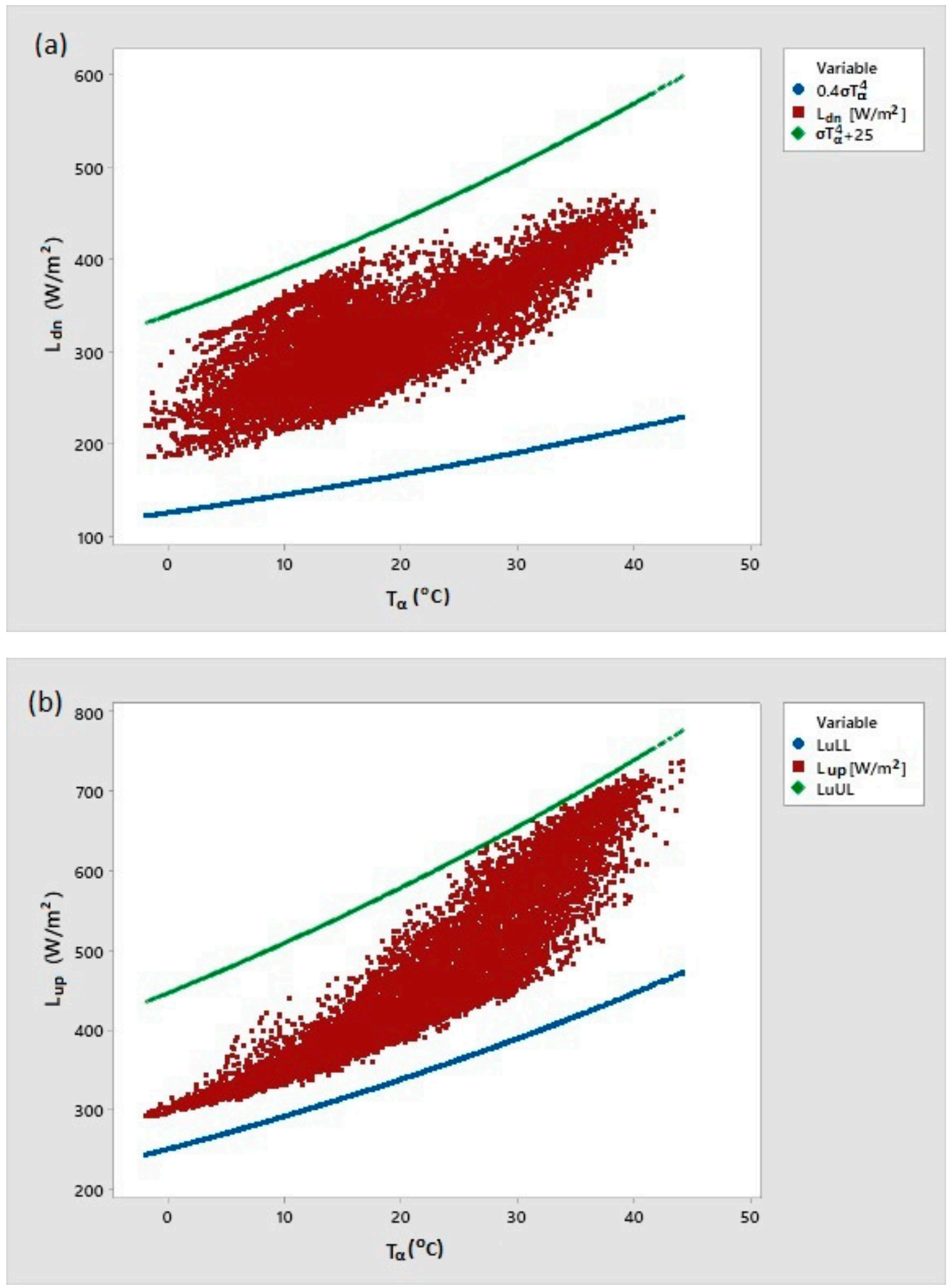

Figure 4. (a) Downward and (b) Upward longwave irradiance testing versus air temperature (Global cross-comparisons, Equations (4) and (5)). Green represents the upper limit and blue the lower limit. 
Table 3. Annual basic statistics of the hourly global $(G)$, reflected $(R)$, net shortwave $\left(R_{n s}\right)$, downward $\left(L_{d n}\right)$, upward $\left(L_{u p}\right)$ and net longwave $\left(R_{n l}\right)$ irradiances in $\mathrm{W} \mathrm{m}^{-2}$, air temperature at the screen level $\left(T_{a}\right)$, air temperature near the ground surface $\left(T_{g}\right)$, relative humidity $(R H)$, and actual vapor pressure (e) for the period of two years (2016-2017).

\begin{tabular}{cccccccccc}
\hline Variable & Unit & $\mathbf{N}$ & Mean & StDev & Min & $\mathbf{Q}_{\mathbf{1}}$ & Median & $\mathbf{Q}_{\mathbf{3}}$ & Max \\
\hline$G$ & $\mathrm{~W} / \mathrm{m}^{2}$ & 7834 & 403.1 & 302.69 & 0.0 & 113.3 & 384.6 & 659.9 & 1020.7 \\
$R$ & $\mathrm{~W} / \mathrm{m}^{2}$ & 8135 & 91.0 & 58.89 & 0.0 & 39.4 & 89.8 & 136.9 & 227.8 \\
$R_{n s}$ & $\mathrm{~W} / \mathrm{m}^{2}$ & 7029 & 355.9 & 230.23 & 7.1 & 145.1 & 344.3 & 551.5 & 850.1 \\
$L_{d n}$ & $\mathrm{~W} / \mathrm{m}^{2}$ & 13,414 & 316.5 & 50.22 & 185.5 & 278.2 & 315.4 & 351.7 & 469.6 \\
$L_{u p}$ & $\mathrm{~W} / \mathrm{m}^{2}$ & 16,121 & 436.9 & 92.04 & 292.7 & 367.0 & 414.8 & 476.1 & 738.0 \\
$R_{n l}$ & $\mathrm{~W} / \mathrm{m}^{2}$ & 13,412 & -105.4 & 57.51 & -293.5 & -133.6 & -93.4 & -71.3 & 3.6 \\
$T_{a}$ & ${ }^{\circ} \mathrm{C}$ & 17,457 & 20.1 & 8.65 & -1.9 & 13.4 & 20.0 & 26.5 & 44.2 \\
$T_{g}$ & ${ }^{\circ} \mathrm{C}$ & 17,424 & 17.9 & 10.13 & -6.2 & 10.0 & 17.5 & 24.8 & 46.2 \\
$R H$ & $\%$ & 17,460 & 60.9 & 21.42 & 10.0 & 43.0 & 63.0 & 79.0 & 99.0 \\
$e$ & $\mathrm{hPa}$ & 17,457 & 14.2 & 5.58 & 3.2 & 10.0 & 13.1 & 17.4 & 31.4 \\
\hline
\end{tabular}

The extreme rare limits can be also obtained by the range of values defined by the limits of 3 times of the standard deviation interval from the mean value. Values outside these thresholds should be considered as extreme values. Using the data set, the intervals for the downward and upward irradiances calculated by the mean $\pm 3^{*} S t D e v$, have the following ranges which are closed to the extremely rare limits: $L_{d n}: 166-467 \mathrm{~W} \mathrm{~m}^{-2}, L_{u p}: 161-713 \mathrm{~W} \mathrm{~m}^{-2}$.

Regarding the range test of the net longwave irradiance $\left(R_{n l}\right)$, Table 3 shows that the data point values are within the suggested limits shown in Table 2 . The annual mean value of $R_{n l}$ is $-105 \mathrm{~W} \mathrm{~m}^{-2}$.

Another quality control test is the step test. This test is based on time consistency which compares the difference between successive measurements. If the difference exceeds an allowed value, then both observations are flagged as suspects. For example, Estevez et al. [38] proposed the following values for different variables: for hourly global irradiance they proposed the value of $555 \mathrm{~W} \mathrm{~m}^{-2}$ and for hourly air temperature the value of $7^{\circ} \mathrm{C}$, while for relative humidity the value of $45 \%$. The data set confirms the limits of the above variables. For the longwave irradiances there is no information in the literature for the difference of two successive measurements. According to the available data set the rate of changes of downward and upward irradiances are $<50 \mathrm{~W} \mathrm{~m}^{-2}$ and $<65 \mathrm{~W} \mathrm{~m}^{-2}$, respectively.

Finally, the persistency test was applied to check the variability of the measurements. When a sensor fails, it will often report a constant value. There is no evidence of such constant values of the given variables through the time series plots (Figure 5). The graph shows that long missing data for both the downward and upward longwave irradiances are observed in the year 2017. The higher values of both variables are recorded during the summer period, while the lower during the winter period, since both of them are related to the air or ground surface temperatures. The variability of upward irradiance is higher than that of downward irradiance. 

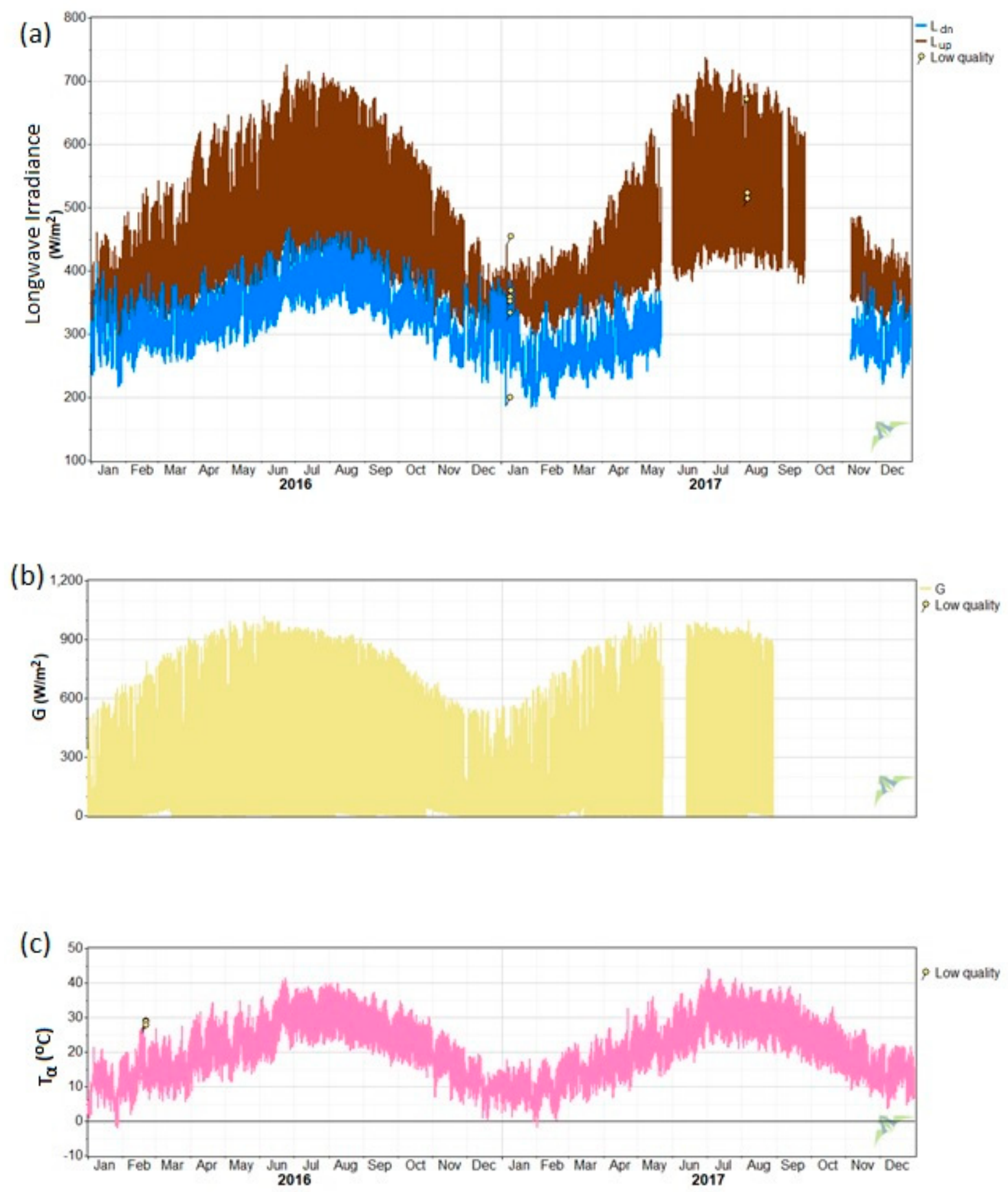

Figure 5. Time series plots of the (a) hourly downward and upward longwave irradiances (b) hourly global shortwave irradiances and (c) hourly air temperatures $\left(T_{a}\right)$ at screen level at Athalassa.

\section{Results and Discussion}

\subsection{Diurnal Variation of Longwave Irradiances}

The daily variation of the hourly downward $\left(L_{d n}\right)$, upward $\left(\mathrm{L}_{\text {up }}\right)$, net longwave irradiances, ground surface temperature and the atmospheric emissivity are shown in Figure 6. The curves follow a sinusoidal pattern (similar to air temperature) with the maximum around 14:00 local time and the minimum around 06:00. The highest mean hourly values of $L_{d n}$ are obtained in July $\left(435 \mathrm{~W} \mathrm{~m}^{-2}\right)$ and the lowest values in February $\left(265 \mathrm{~W} \mathrm{~m}^{-2}\right)$. The highest mean hourly values of $L_{u p}$ are obtained again in July $\left(692 \mathrm{~W} \mathrm{~m}^{-2}\right)$ 
and the lowest values in January $\left(330 \mathrm{~W} \mathrm{~m}^{-2}\right)$. Since $L_{u p}$ is always higher than $L_{d n}$, the mean hourly net longwave irradiance $\left(R_{n l}=L_{d n}-L_{u p}\right)$ is always negative, ranging from $-47 \mathrm{~W} \mathrm{~m}^{-2}$ in the morning to $-265 \mathrm{~W} \mathrm{~m}^{-2}$ in the midday. The lower negative values of the hourly $R_{n l}$ during midday are associated with the higher ground surface temperatures which are recorded at the station (Figure $6 \mathrm{c}, \mathrm{d}$ ). Similar variation of the above variables was also obtained for the period 2013-2015 [9]. The average hourly emissivity $\left(\varepsilon_{a}\right)$ is $0.77 \pm 0.08$ and shows slightly lower values during the winter months and around 0.8 during the summer months when the weather conditions are more stable (Figure 6e).
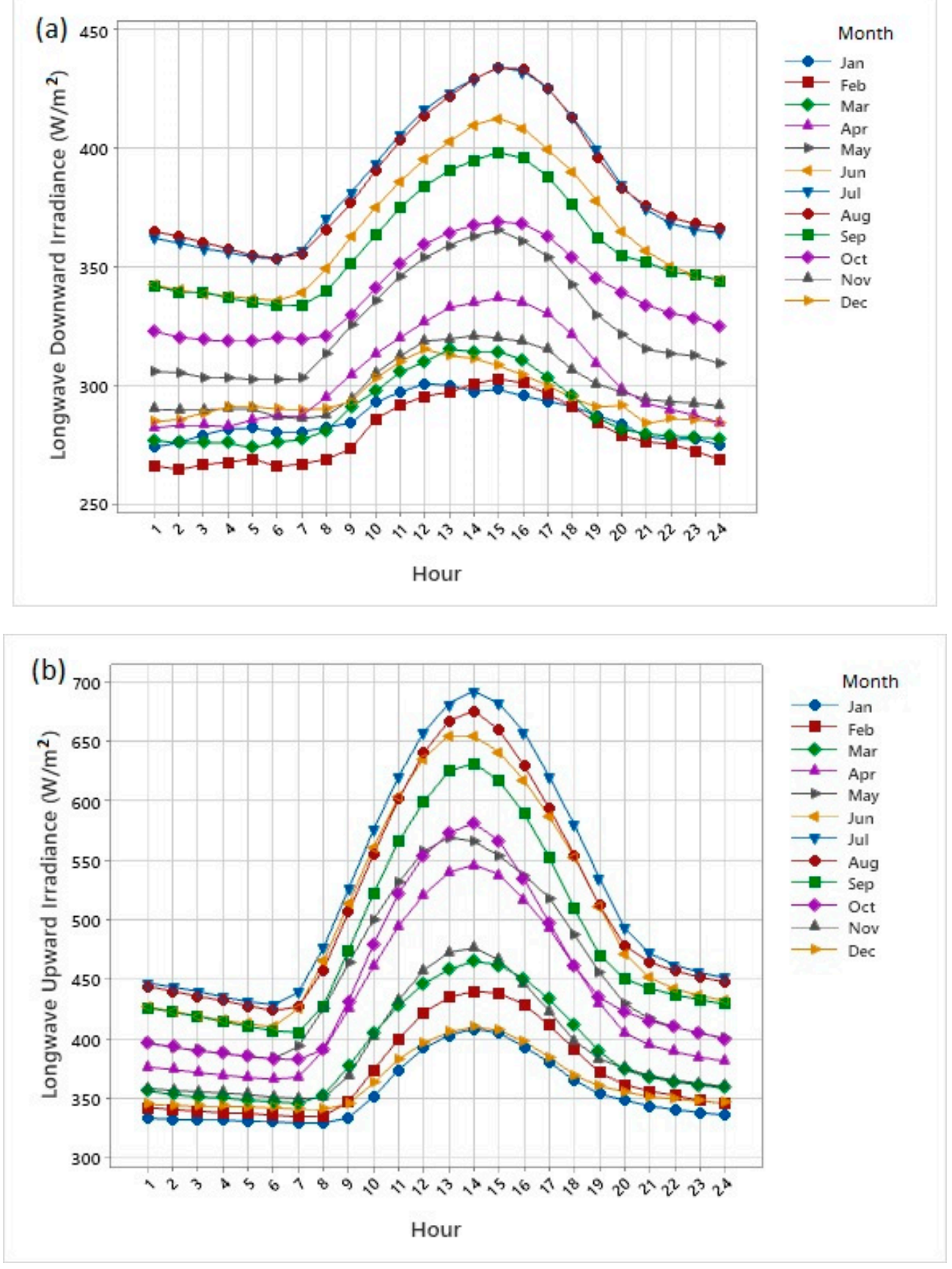

Figure 6. Diurnal variation of the (a) downward $\left(L_{d n}\right),(\mathbf{b})$ upward $\left(L_{u p}\right)$, (c) net longwave irradiances $\left(R_{n l}\right)$ (d) ground surface temperatures $\left(T_{g}\right)$ and (e) Annual variability of the hourly estimated effective air emissivity $\left(\varepsilon_{a}\right)$. 

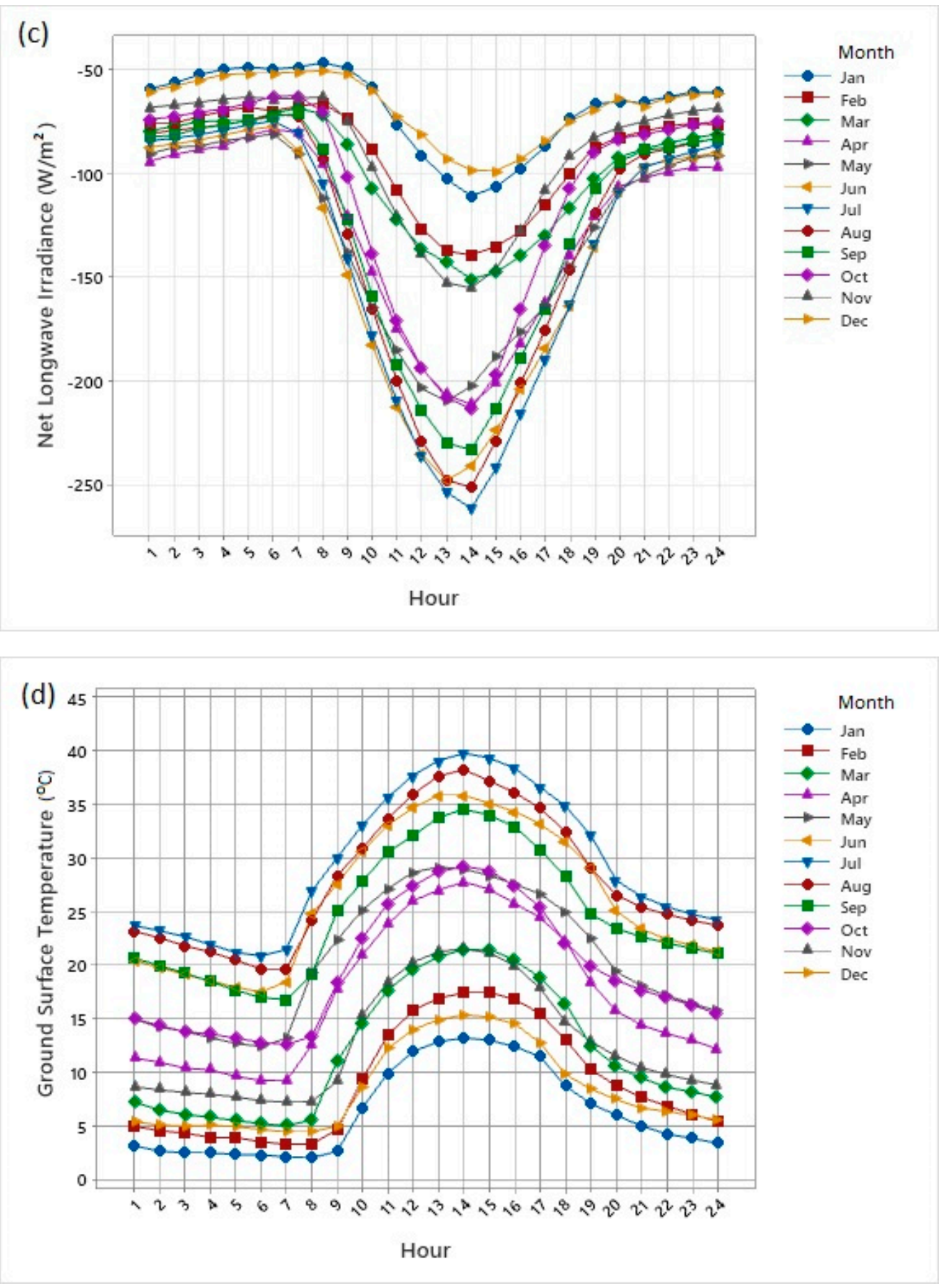

Figure 6. Conts. 


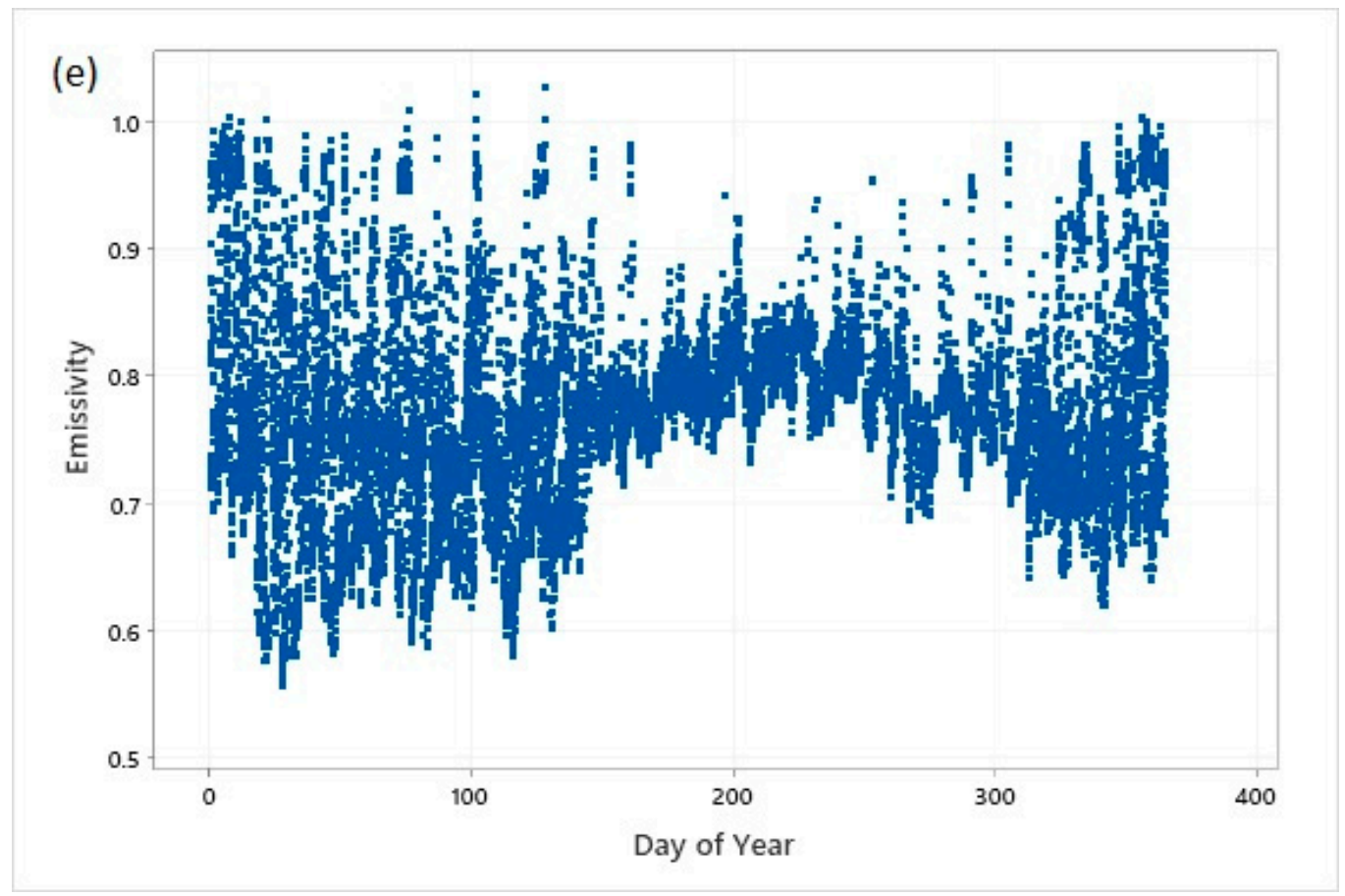

Figure 6. Conts.

\subsection{Seasonal Variation of Longwave Irradiances}

The monthly statistics of the longwave and shortwave irradiances and their associated standard deviations and extreme values are presented in Table 4 . The monthly means of all the radiation components are also shown in Figure 7. The monthly means of $L_{d n}$ range between 280 and $387 \mathrm{~W} / \mathrm{m}^{2}$ with the lowest values in the winter months and the highest during the summer months. Similar variation is observed for the upward longwave irradiance ranging from 355 to $529 \mathrm{~W} / \mathrm{m}^{2}$. The net longwave irradiance is always negative, ranging from -68 in the winter months to $-140 \mathrm{~W} / \mathrm{m}^{2}$ in the summer months. The lower negative values during the summer months are associated with the higher ground surface temperatures. The mean values of global irradiance are comparable to the upward longwave irradiances $\left(L_{u p}\right)$. However, the maximum of global irradiances may exceed the value of $1000 \mathrm{~W} / \mathrm{m}^{2}$, while $L_{\text {up }}$ reached the value of $738 \mathrm{~W} / \mathrm{m}^{2}$. Furthermore, the monthly variability of longwave irradiances expressed by their standard deviation is much lower than the respective values of global irradiance. The mean values of the reflected irradiances range mainly between 50 and $130 \mathrm{~W} / \mathrm{m}^{2}$ with the highest occurring in the summer months. The net shortwave irradiance is positive throughout the year, ranging from 195 to $444 \mathrm{~W} / \mathrm{m}^{2}$. However, the net allwave irradiances are positive during the first 10 months of the year and slightly below zero during the last two months of the year (November and December). 
Table 4. Monthly statistics of longwave (LW) and shortwave (SW) irradiances and their associated standard deviations (Std) and extreme values in $\mathrm{W} / \mathrm{m}^{2}$.

\begin{tabular}{|c|c|c|c|c|c|c|c|c|c|c|c|c|c|c|c|}
\hline Rad. & Stat. & Var. & Jan & Feb & Mar & Apr & May & Jun & Jul & Aug & Sep & Oct & Nov & Dec & All \\
\hline LW & & $L_{d n}$ & 286 & 280 & 290 & 304 & 327 & 367 & 387 & 387 & 359 & 339 & 300 & 295 & 316 \\
\hline LW & & $L_{u p}$ & 355 & 372 & 390 & 432 & 457 & 507 & 529 & 516 & 487 & 450 & 391 & 363 & 437 \\
\hline LW & & $R_{n l}$ & -69 & -92 & -100 & -128 & -130 & -140 & -140 & -132 & -126 & -111 & -91 & -68 & -105 \\
\hline SW & Mean & $G$ & 236 & 310 & 386 & 446 & 442 & 494 & 498 & 487 & 439 & 366 & 300 & 206 & 403 \\
\hline SW & & $R$ & 49 & 71 & 85 & 92 & 89 & 112 & 127 & 119 & 108 & 94 & 65 & 48 & 91 \\
\hline SW & & $R_{n s}$ & 231 & 288 & 336 & 399 & 393 & 444 & 429 & 395 & 375 & 324 & 249 & 195 & 356 \\
\hline AW & & $R_{n}$ & 25 & 32 & 64 & 85 & 96 & 199 & 227 & 193 & 64 & 37 & -29 & -29 & 75 \\
\hline LW & & $L_{d n}$ & 45 & 41 & 35 & 37 & 36 & 35 & 30 & 31 & 32 & 25 & 32 & 38 & 50 \\
\hline LW & & $L_{u p}$ & 32 & 45 & 49 & 71 & 73 & 92 & 95 & 88 & 80 & 70 & 49 & 29 & 92 \\
\hline LW & & $\boldsymbol{R}_{n l}$ & 45 & 40 & 44 & 57 & 59 & 64 & 67 & 63 & 60 & 55 & 43 & 38 & 58 \\
\hline SW & Std & $G$ & 196 & 236 & 276 & 314 & 317 & 338 & 337 & 313 & 290 & 260 & 210 & 173 & 303 \\
\hline SW & & $R$ & 34 & 44 & 51 & 51 & 53 & 59 & 65 & 64 & 62 & 51 & 43 & 37 & 59 \\
\hline SW & & $R_{n s}$ & 152 & 177 & 215 & 245 & 249 & 250 & 245 & 236 & 213 & 185 & 158 & 133 & 230 \\
\hline AW & & $R_{n}$ & 131 & 158 & 196 & 221 & 222 & 273 & 276 & 258 & 186 & 154 & 110 & 98 & 212 \\
\hline LW & & $L_{d n}$ & 185 & 186 & 217 & 229 & 243 & 303 & 333 & 333 & 294 & 284 & 241 & 222 & 185 \\
\hline LW & & $L_{u p}$ & 293 & 298 & 323 & 326 & 359 & 384 & 404 & 404 & 376 & 352 & 313 & 308 & 293 \\
\hline LW & & $R_{n l}$ & -179 & -190 & -240 & -279 & -282 & -284 & -293 & -293 & -274 & -256 & -205 & -156 & -293 \\
\hline SW & Min & $G$ & 0 & 0 & 0 & 0 & 0 & 0 & 0 & 0 & 0 & 0 & 0 & 0 & 0 \\
\hline SW & Thm & $R$ & 2 & 2 & 2 & 2 & 2 & 0 & 8 & 1 & 0 & 4 & 0 & 0 & 0 \\
\hline SW & & $R_{n s}$ & 14 & 8 & 9 & 10 & 10 & 15 & 18 & 7 & 8 & 17 & 9 & 9 & 7 \\
\hline AW & & $R_{n}$ & -146 & -145 & -147 & -147 & -153 & -114 & -116 & -113 & -134 & -122 & -192 & -156 & -192 \\
\hline LW & & $L_{d n}$ & 413 & 397 & 383 & 409 & 423 & 470 & 463 & 464 & 454 & 423 & 404 & 397 & 470 \\
\hline LW & & $L_{u p}$ & 488 & 532 & 559 & 635 & 648 & 726 & 738 & 713 & 684 & 629 & 534 & 454 & 738 \\
\hline LW & & $R_{n l}$ & 4 & 4 & -4 & -1 & -4 & -9 & -45 & -31 & -10 & -1 & -1 & -1 & 4 \\
\hline SW & Max & $G$ & 672 & 792 & 915 & 994 & 995 & 1021 & 986 & 999 & 887 & 805 & 685 & 551 & 1021 \\
\hline SW & & $R$ & 137 & 167 & 194 & 217 & 198 & 212 & 223 & 228 & 214 & 177 & 144 & 150 & 228 \\
\hline SW & & $R_{n s}$ & 563 & 662 & 755 & 850 & 841 & 829 & 779 & 783 & 709 & 628 & 540 & 455 & 850 \\
\hline $\mathrm{AW}$ & & $R_{n}$ & 416 & 550 & 562 & 636 & 630 & 794 & 771 & 783 & 478 & 394 & 371 & 407 & 794 \\
\hline
\end{tabular}

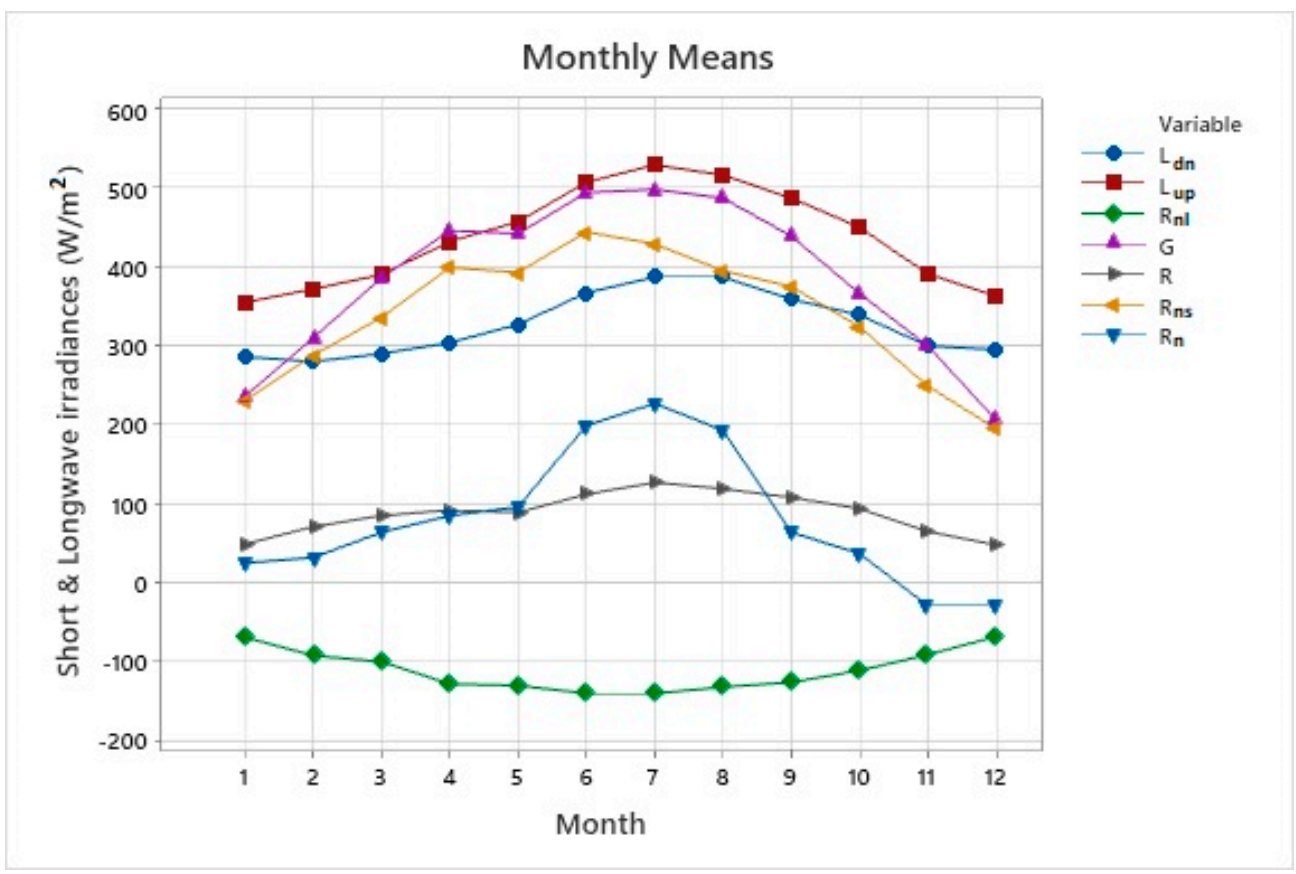

Figure 7. Monthly mean values of the short and longwave irradiances including the net allwave irradiances in $\mathrm{W} / \mathrm{m}^{2}$. 


\subsection{Frequency Distribution of Longwave Irradiances}

Figure 8 shows the annual frequency distributions of the hourly downward and upward irradiances. As can be seen $L_{d n}$ irradiances follow the normal distribution function, while $L_{u p}$ follows an almost normal distribution but with a long positive tail. The annual cumulative density function curves $(C D F)$ of the two variables are presented in Figure 9. As indicated from the graph, in $75 \%$ of the irradiances, $L_{d n}$ at Athalassa are lower than $350 \mathrm{~W} \mathrm{~m}^{-2}$. For the upward longwave irradiance $\left(L_{u p}\right)$, for the same probability, the irradiances are lower than $480 \mathrm{~W} \mathrm{~m}^{-2}$.

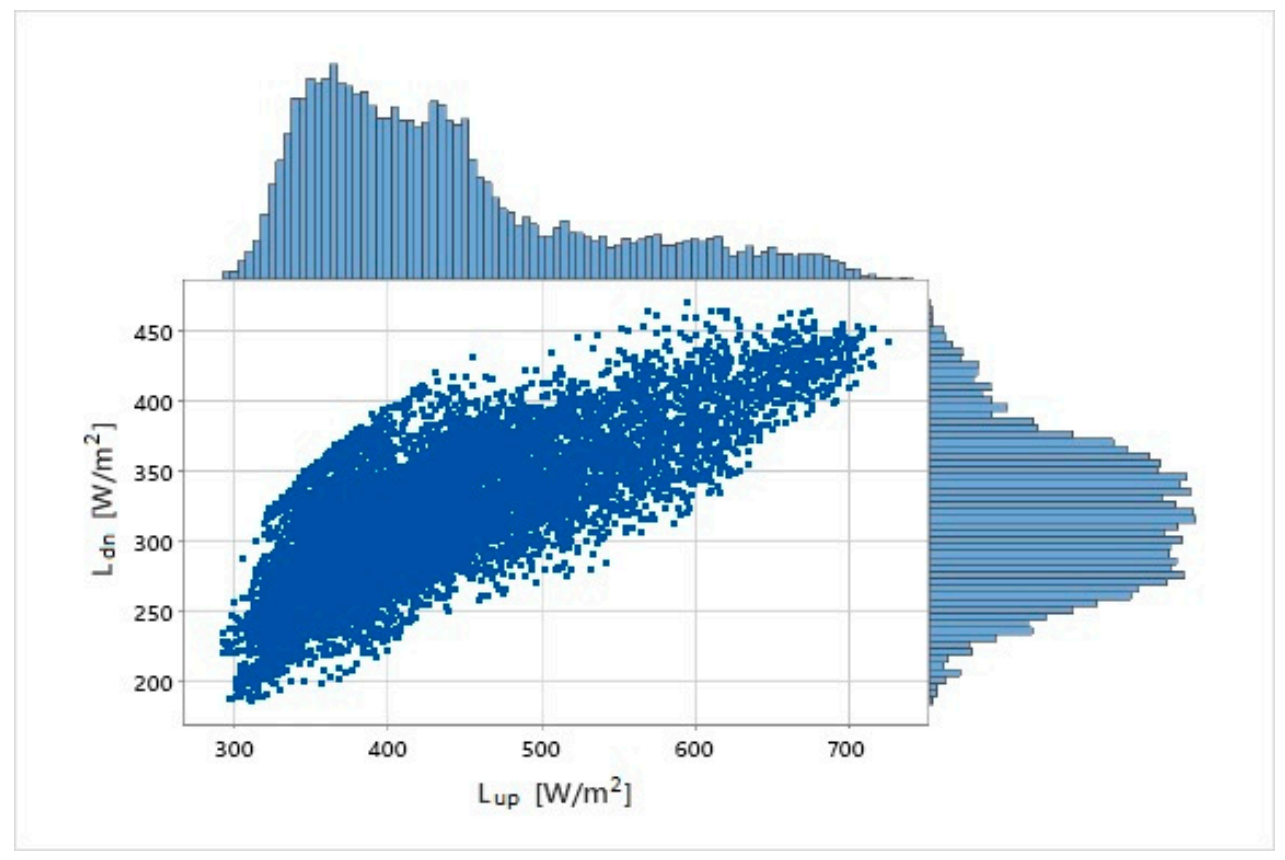

Figure 8. Marginal plot of the hourly $L_{d n}$ and $L_{u p}$ with the annual frequency distributions of the two variables at Athalassa.

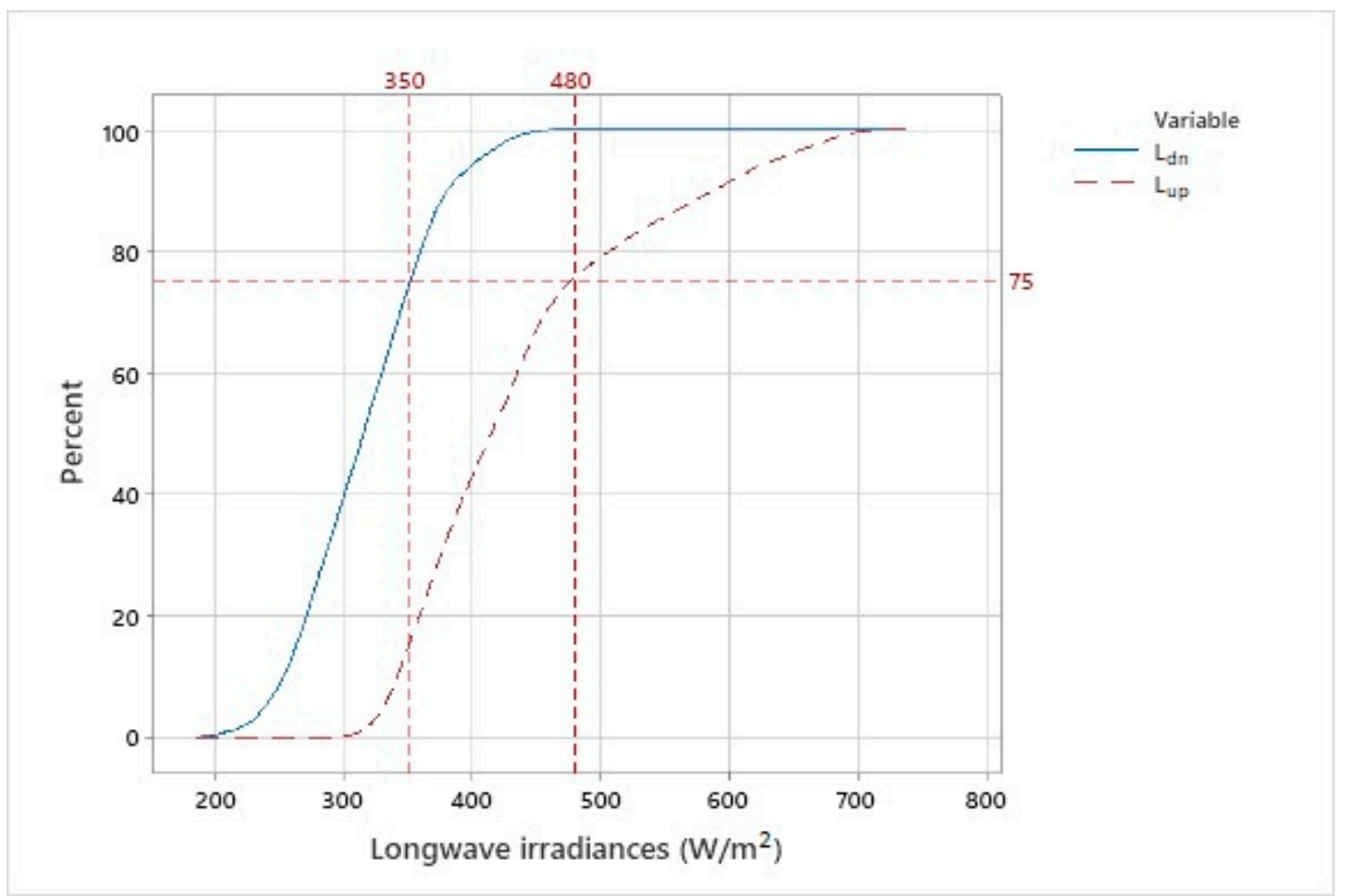

Figure 9. Cumulative density function $(C D F)$ for $L_{d n}$ and $L_{u p}$ at Athalassa. 
The monthly variation of both variables is shown in Figure 10. The outliers are presented with an asterisk and as seen, significant number of outliers of $L_{d n}$ is observed in June and during the period of September to November. In the case of $L_{u p}$, outliers are observed at the beginning of the year (in the first three months) and towards the end of the year (in the last two months).
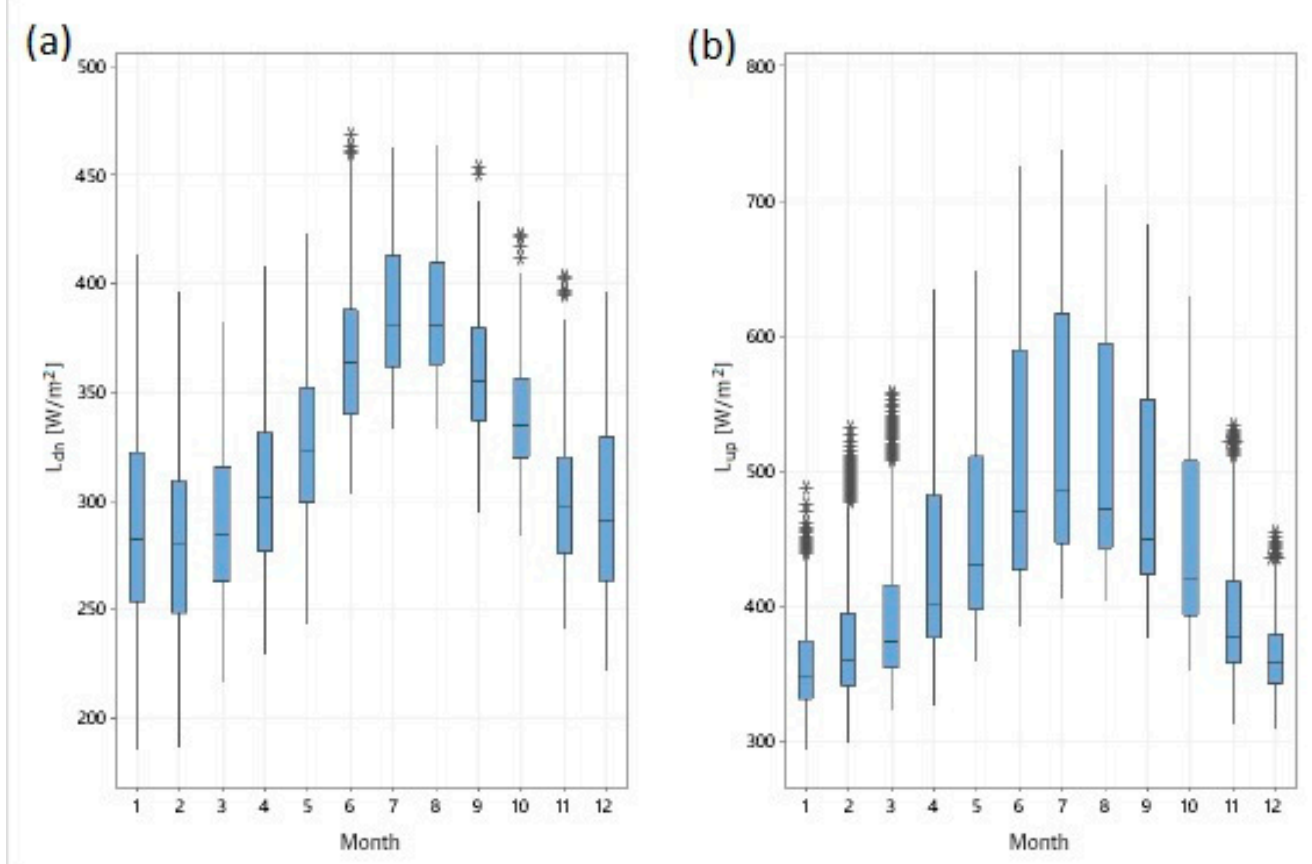

Figure 10. Monthly boxplots of (a) downward $\left(L_{d n}\right)$ and (b) upward $\left(L_{u p}\right)$ longwave irradiances at Athalassa.

\subsection{Statistical Relationships of Hourly Values}

The variables illustrated in Figure 8, can be expressed by quadratic equations. However, the coefficient of determination is relatively low:

$$
L_{d n}=-10.01+1.058 * L_{u p}-0.0006 * L_{u p}^{2}, R^{2}=0.57
$$

The quadratic equations of the relationships between the hourly longwave irradiances with air $\left(T_{a}\right)$ and ground surface temperatures $\left(T_{g}\right)$ are shown below:

$$
\begin{aligned}
& L_{d n}=251.9+2.035 * T_{a}+0.068 * T_{a}^{2}, R^{2}=0.62 \\
& L_{d n}=258.3+3.195 * T_{g}+0.021 * T_{g}^{2}, R^{2}=0.60 \\
& L_{u p}=325.1+0.152 * T_{a}+0.227 * T_{a}^{2}, R^{2}=0.88 \\
& L_{u p}=329.2+1.969 * T_{g}+0.172 * T_{g}^{2}, R^{2}=0.96
\end{aligned}
$$

It is evident that $L_{u p}$ has strong relationships with both air and ground surface temperatures. The coefficient of determination of the relationship of $L_{u p}$ and $T_{g}$ is closed to 1.

\subsection{Daily Data}

Figure 11 shows the temporal evolution of the daily downward and upward longwave irradiation. As can be seen, during the winter and spring season a strong variability occurs. The maximum daily value of $L_{d n}$ is $35.2 \mathrm{MJ} \mathrm{m}^{-2}$ while the respective minimum value is $17.4 \mathrm{MJ} \mathrm{m}^{-2}$. The maximum value of $L_{u p}$ is $48.3 \mathrm{MJ} \mathrm{m}^{-2}$ and the minimum value is $26.3 \mathrm{MJ} \mathrm{m}^{-2}$. 


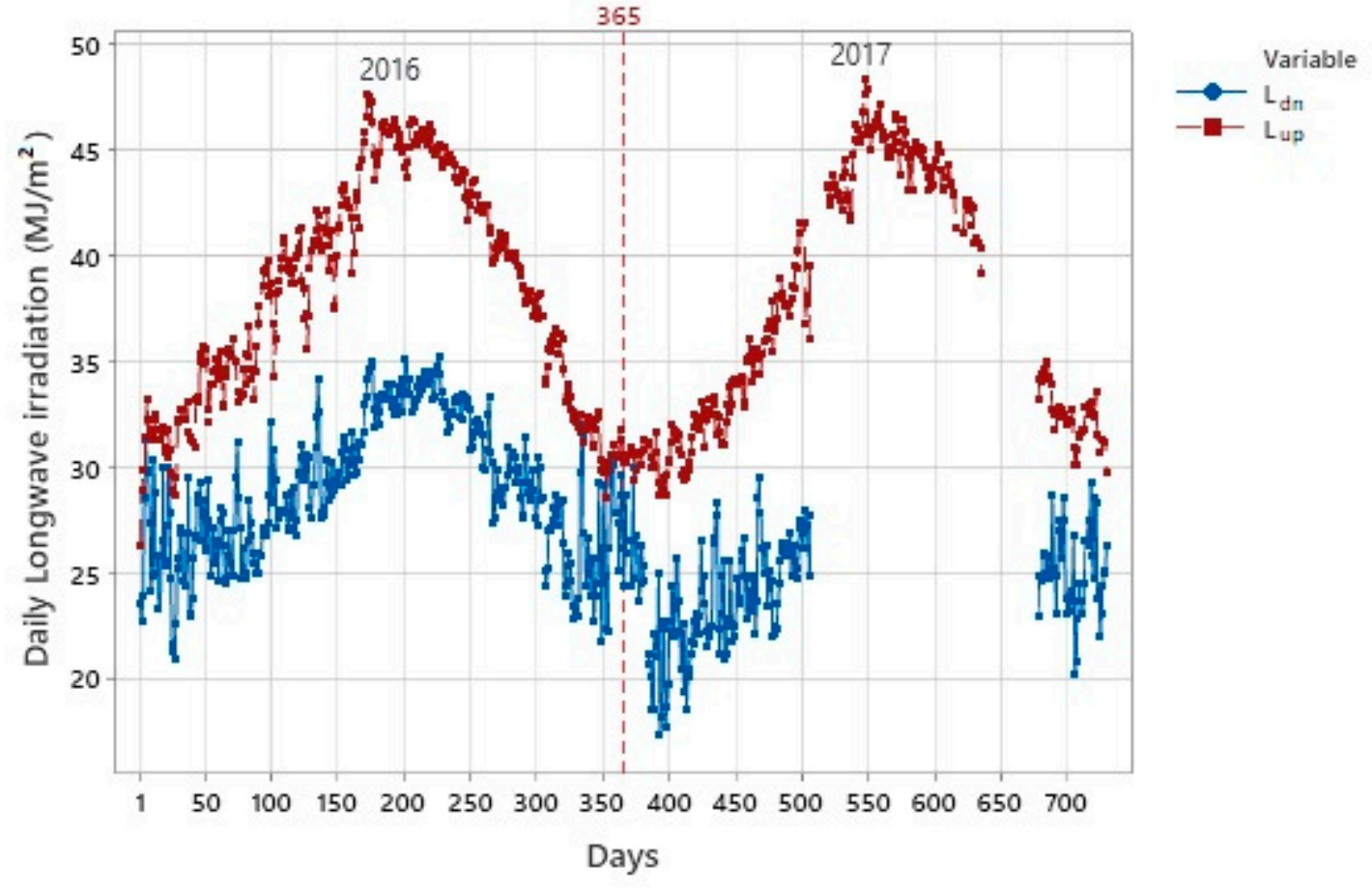

Figure 11. Daily downward and upward longwave irradiation at Athalassa, during the period 2016-2017.

The monthly statistics of daily downward and upward longwave irradiation is shown in Table 5, which presents the following statistical parameters: number of observations $(\mathrm{N})$, arithmetic mean (Mean), standard deviation (StDev), coefficient of variation in percent $(\mathrm{CV}(\%))$, minimum (Min), the first and third quartiles (Q1 and Q3), and median and maximum (Max). Generally, the median values are close to the mean values. The variability of $L_{u p}$ is lower than $L_{d n}$, since its coefficient of variation (CV\%) ranges from $2 \%$ to $5 \%$. $L_{d n}$ has higher variability during the winter and spring months.

The monthly mean daily values of all radiation components are plotted in Figure 12. Longwave irradiation shows the highest mean daily values comparing to the other shortwave radiation components. $L_{u p}$ has the highest mean daily values from all the radiation components. The higher values of both longwave irradiation are observed during the summer months due to higher air and ground surface temperatures. As a result, the net longwave irradiation is always negative ranging from -5.9 to $-12.1 \mathrm{MJ} / \mathrm{m}^{2}$. The net longwave irradiation represents the radiative cooling potential. On the other hand, the net shortwave irradiation $\left(R_{n s}\right)$ ranges from 6.6 to $22.4 \mathrm{MJ} / \mathrm{m}^{2}$. Therefore, the net daily irradiation is positive ranging from 1.3 to $10.5 \mathrm{MJ} / \mathrm{m}^{2}$. The pattern of $R_{n}$ follows the same as the $R_{n s}$, i.e., higher values during the summer season. The variability of the net short, long and allwave radiation components is presented in Figure 13. The highest variability is observed during the winter and spring months as it is indicated by the length of the boxplots.

Figure 14 shows the $\mathrm{CDF}$ curves of the daily downward and upward longwave irradiation. As can be seen in both cases in $60 \%$ of the days the $L_{d n}$ is lower than $28.3 \mathrm{MJ} \mathrm{m}^{-2}$ and $L_{u p}$ is lower than $40 \mathrm{MJ} \mathrm{m}^{-2}$. 
Table 5. Statistics of daily downward and upward longwave irradiation $\left(\mathrm{MJ} \mathrm{m}^{-2}\right)$ at Athalassa.

\begin{tabular}{|c|c|c|c|c|c|c|c|c|c|}
\hline \multicolumn{10}{|c|}{$L_{d n}\left(\mathrm{MJ} / \mathrm{m}^{2}\right)$} \\
\hline Month & $\mathbf{N}$ & Mean & StDev & CV $(\%)$ & Min & Q1 & Median & Q3 & Max \\
\hline 1 & 58 & 24.7 & 3.3 & 13.4 & 17.4 & 22.5 & 24.8 & 26.8 & 31.2 \\
\hline 2 & 56 & 24.2 & 3.0 & 12.3 & 17.7 & 22.2 & 24.4 & 26.5 & 29.5 \\
\hline 3 & 62 & 25.0 & 2.3 & 9.0 & 20.9 & 22.9 & 24.9 & 26.6 & 31.1 \\
\hline 4 & 60 & 26.3 & 2.3 & 8.7 & 22.0 & 24.5 & 26.8 & 27.9 & 32.1 \\
\hline 5 & 53 & 28.3 & 2.1 & 7.5 & 24.8 & 26.4 & 28.1 & 29.7 & 34.1 \\
\hline 6 & 30 & 31.7 & 1.7 & 5.5 & 29.2 & 30.3 & 31.2 & 33.0 & 35.0 \\
\hline 7 & 31 & 33.4 & 0.7 & 2.0 & 32.5 & 32.9 & 33.4 & 33.9 & 35.1 \\
\hline 8 & 31 & 33.4 & 0.9 & 2.8 & 31.7 & 32.5 & 33.3 & 34.2 & 35.2 \\
\hline 9 & 30 & 31.0 & 1.8 & 5.8 & 27.3 & 29.9 & 31.4 & 32.5 & 33.4 \\
\hline 10 & 31 & 29.3 & 1.1 & 3.6 & 27.3 & 28.5 & 29.3 & 29.9 & 31.4 \\
\hline 11 & 51 & 25.8 & 2.0 & 7.7 & 22.9 & 24.6 & 25.4 & 27.4 & 32.0 \\
\hline 12 & 61 & 25.4 & 2.5 & 9.8 & 20.2 & 23.7 & 25.1 & 26.8 & 31.4 \\
\hline All & 554 & 27.3 & 3.8 & 13.8 & 17.4 & 24.7 & 27.1 & 29.9 & 35.2 \\
\hline \multicolumn{10}{|c|}{$L_{u p}\left(\mathrm{MJ} / \mathrm{m}^{2}\right)$} \\
\hline Month & $\mathbf{N}$ & Mean & StDev & CV(\%) & Min & Q1 & Median & Q3 & Max \\
\hline 1 & 58 & 30.6 & 1.3 & 4.1 & 26.3 & 29.8 & 30.6 & 31.6 & 33.2 \\
\hline 2 & 56 & 32.1 & 1.8 & 5.5 & 28.6 & 31.0 & 31.9 & 33.1 & 35.7 \\
\hline 3 & 62 & 33.7 & 1.4 & 4.2 & 30.9 & 32.7 & 33.8 & 34.6 & 36.7 \\
\hline 4 & 60 & 37.3 & 2.1 & 5.5 & 32.8 & 35.5 & 37.7 & 39.1 & 40.8 \\
\hline 5 & 53 & 39.5 & 1.8 & 4.5 & 35.6 & 37.7 & 39.8 & 41.1 & 42.1 \\
\hline 6 & 58 & 43.8 & 1.8 & 4.2 & 39.2 & 42.6 & 43.3 & 45.3 & 47.5 \\
\hline 7 & 62 & 45.7 & 0.9 & 1.9 & 43.7 & 45.1 & 45.8 & 46.2 & 48.3 \\
\hline 8 & 62 & 44.6 & 0.8 & 1.9 & 43.0 & 43.9 & 44.7 & 45.1 & 46.1 \\
\hline 9 & 53 & 42.0 & 1.3 & 3.1 & 39.1 & 40.8 & 42.3 & 42.8 & 44.2 \\
\hline 10 & 31 & 38.9 & 1.2 & 3.1 & 37.0 & 37.9 & 38.6 & 40.0 & 40.9 \\
\hline 11 & 51 & 33.8 & 1.5 & 4.3 & 31.6 & 32.4 & 33.9 & 34.8 & 36.6 \\
\hline 12 & 61 & 31.4 & 1.0 & 3.3 & 28.5 & 30.6 & 31.4 & 32.2 & 33.5 \\
\hline All & 667 & 37.8 & 5.6 & 14.7 & 26.3 & 32.4 & 37.6 & 43.0 & 48.3 \\
\hline
\end{tabular}

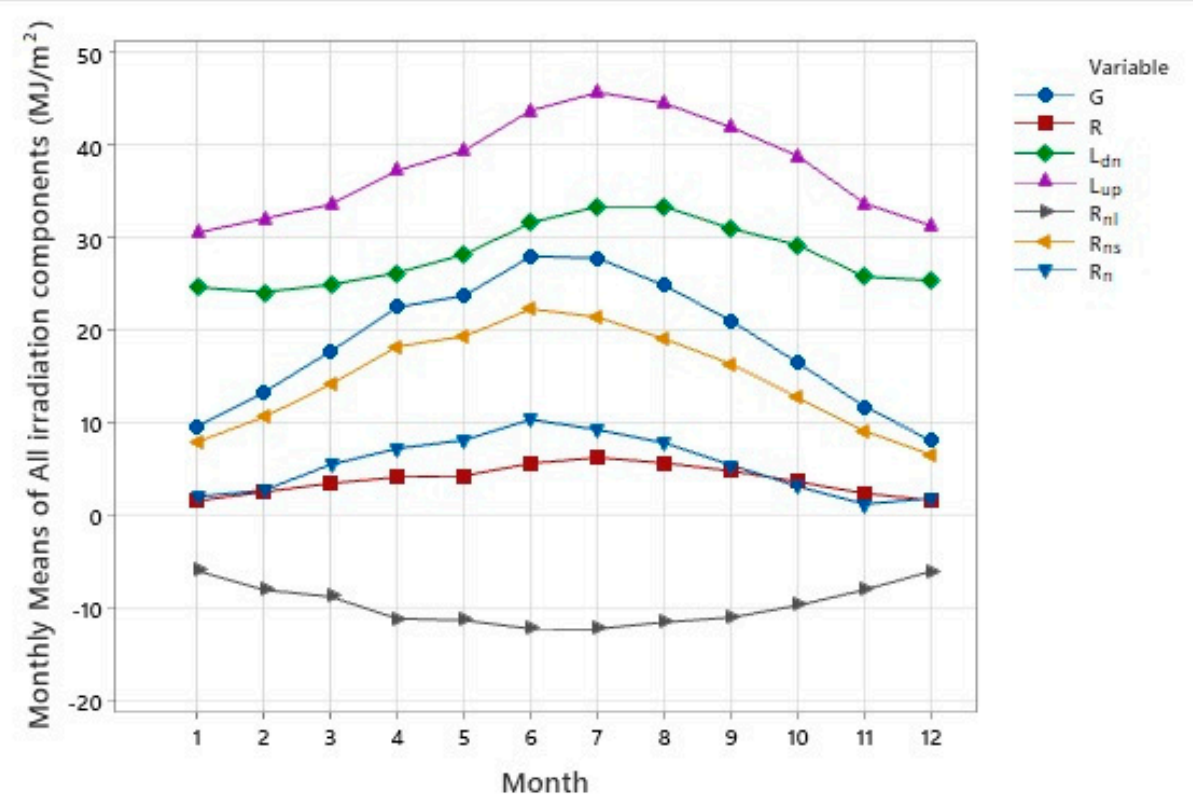

Figure 12. Monthly mean daily longwave and shortwave irradiation components. 

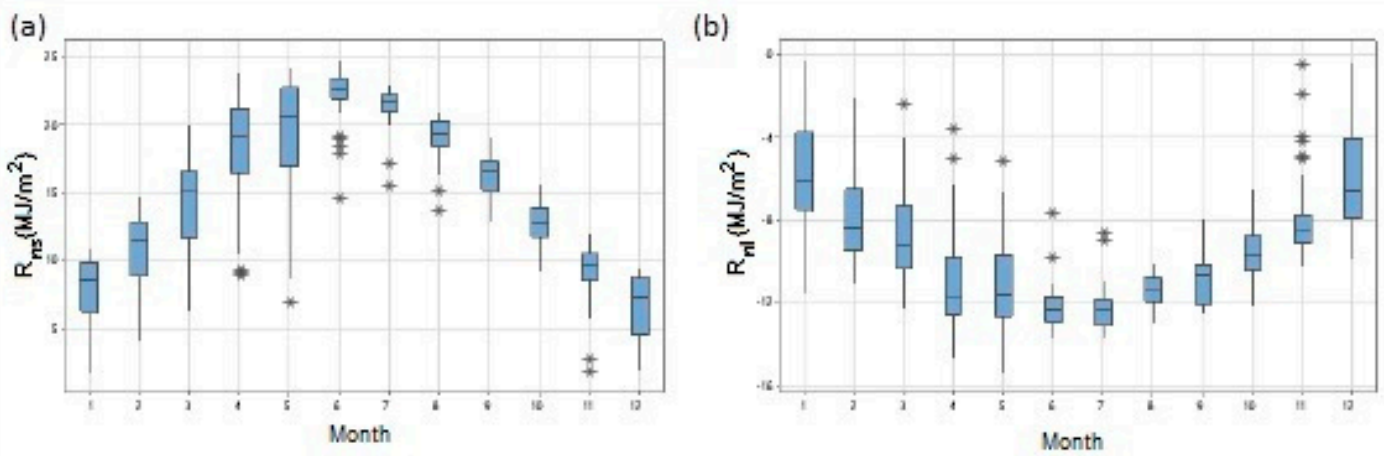

(c)

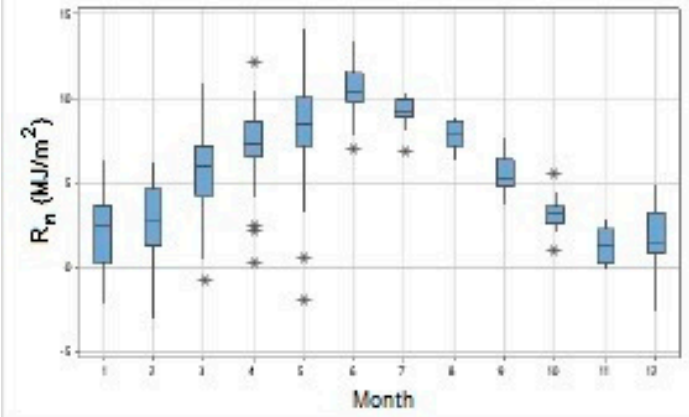

Figure 13. Boxplots of the daily (a) net shortwave $\left(R_{n s}\right),(\mathbf{b})$ net longwave $\left(R_{n l}\right)$, and (c) net allwave irradiation $\left(R_{n}\right)\left(\mathrm{MJ} / \mathrm{m}^{2}\right)$.

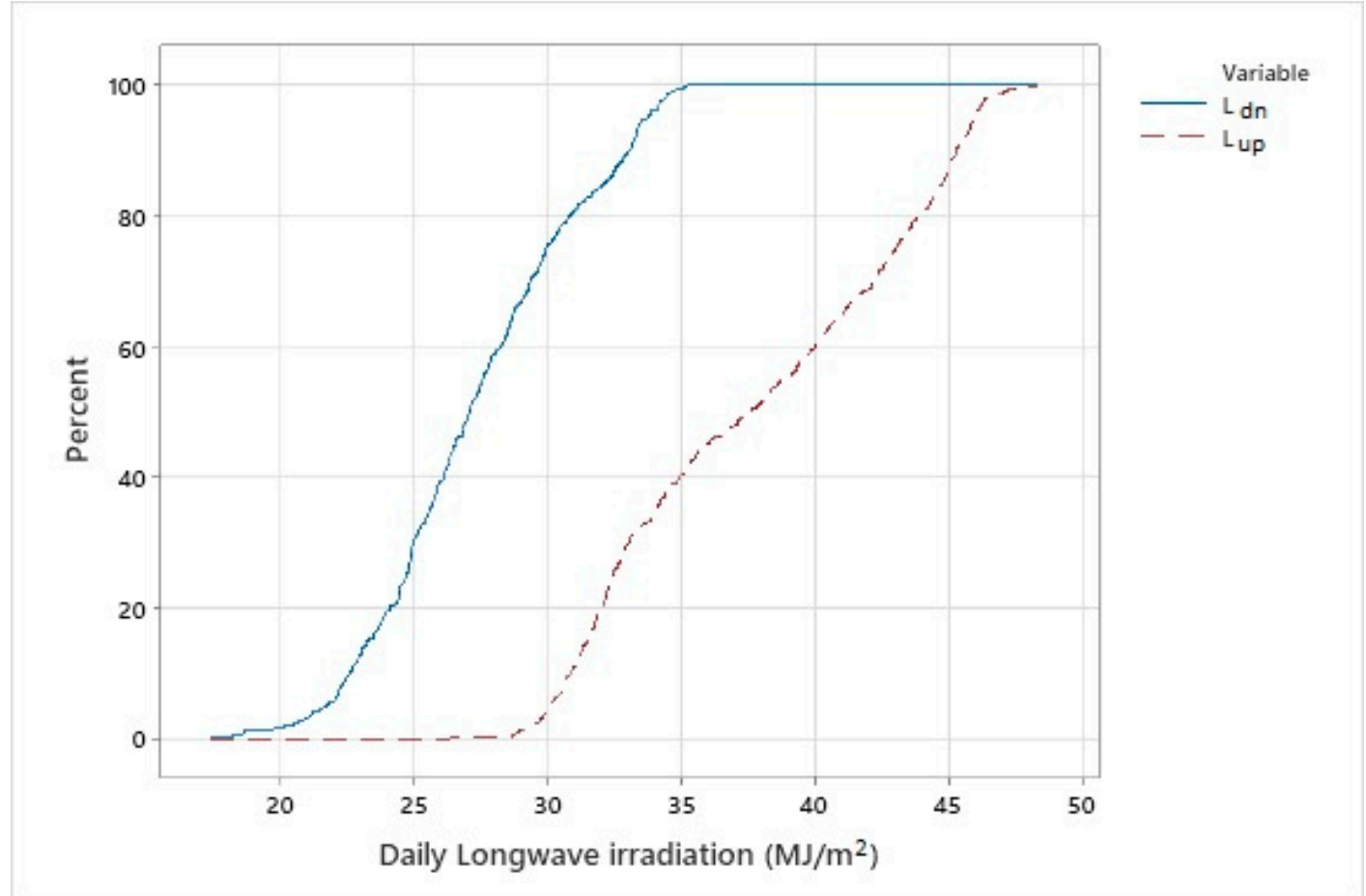

Figure 14. Cumulative density function (CDF) of the daily downward $\left(L_{d n}\right)$ and upward $\left(L_{u p}\right)$ longwave irradiation $\left(\mathrm{MJ} \mathrm{m}^{-2}\right)$ at Athalassa. 


\subsection{Relationships with Daily Data}

A linear relationship was established between the daily downward and upward longwave irradiation $\left(\mathrm{MJ} \mathrm{m}^{-2}\right)$ :

$$
L_{d n d}=5.581+0.597 * L_{\text {upd }}, R^{2}=0.66
$$

There is also a strong correlation between the daily longwave upward irradiation and the daily shortwave reflected irradiation since both are depended on the properties of the soil (Figure 15):

$$
L_{\text {upd }}=28.88+1.270 * R_{d}+0.204 * R_{d}^{2}, R^{2}=0.79
$$

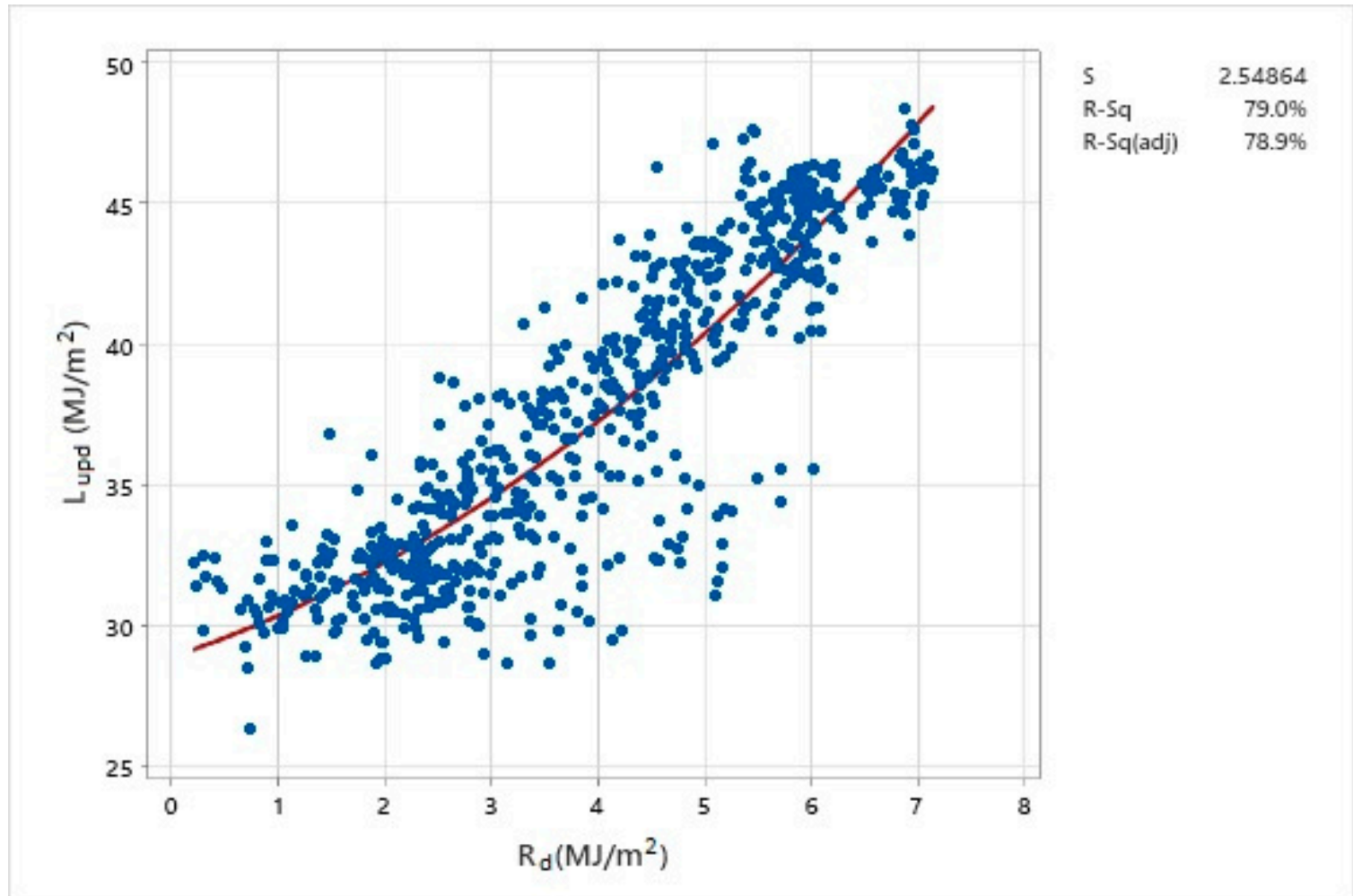

Figure 15. Quadratic relationship between the daily longwave upward irradiation $\left(\mathrm{L}_{\text {upd }}\right)$ and the daily shortwave reflected irradiation $\left(R_{d}\right)$.

\subsection{Parameterizing Daytime Longwave Downward Radiation}

\subsubsection{Clear-Sky Conditions}

Since the downward longwave radiation is greatly affected by air temperature and/or vapor pressure at the screen level parameterizing was based on these variables. Pashiardis et al. [9] have estimated daytime longwave downward irradiance under clear sky conditions using five different models. For this purpose, hourly temperature and relative humidity data were used to estimate $L_{d n}$. The classification of the clear-sky conditions was based on the value of the clearness index $k_{t}$, which is defined as the hourly ratio of the measured global solar irradiance to the value of extraterrestrial horizontal solar irradiance $\left(k_{t}=G / G_{0}\right)$. Then, the sky can be considered as clear when $\left(k_{t} \geq 0.65\right)$, as partly cloudy when $\left(0.35 \leq k_{t}<0.65\right)$, and cloudy when $\left(k_{t} \leq 0.35\right)[39]$.

The best performance of the test models was obtained with Idso [40] and Brunt's [41] models using local calibrated coefficients based on data measurements covering the period 2013-2014 (training dataset). The equations involved in the calculations of the longwave 
downward irradiance under clear sky conditions $\left(L_{d n c}\right)$ with local calibrated coefficients have the following form:

$$
\begin{gathered}
L_{d n c}=\left[0.71+4.09 * 10^{-5} e * \exp \left(1500 / T_{a}\right)\right] * \sigma * T_{a}^{4}(\text { Idso model }) \\
L_{d n c}=\left(0.62+0.046 * e^{0.5}\right) * \sigma * T_{a}^{4}(\text { Brunt model })
\end{gathered}
$$

where, $e$ is the actual vapor pressure in $\mathrm{hPa}, T_{a}$ is the air temperature at screen level in Kelvin and $\sigma$ is the Stefan-Boltzman constant. The above models were tested with the current data set hourly values. The performance of the above models was based on the root-mean-square error (RMSE), and the correlation between the estimated $\left(E_{i}\right)$ and the measured irradiance values $\left(M_{i}\right)$. The RMSE has the following form:

$$
\operatorname{RMSE}=\left[\frac{1}{n} \sum_{i=1}^{n}\left(E_{i}-M_{i}\right)^{2}\right]^{0.5}
$$

where $n$ is the number of data pairs. The results of the evaluation of both models for the clear sky conditions are shown in Table 6. The Table shows that the slope of the lines and the coefficients of determinations are close to one for both clear sky models. However, Brunt's model shows slightly better performance with respect to Idso's model, since it has slightly lower RMSE compared to Idso's model.

Table 6. Comparison of statistical estimators of the two calibrated daylight downward longwave irradiance models under (a) clear-sky and (b) all-sky conditions at Athalassa using the current data set (2016-2017).

\begin{tabular}{llcccc}
\hline Sky Conditions & Model & Variable & Slope & $\mathbf{R}^{\mathbf{2}}$ & RMSE (W/m $\mathbf{m}^{\mathbf{2}}$ \\
\hline \multirow{2}{*}{ Clear sky } & Idso & $L_{n d c}$ & 1.017 & 0.997 & 21.819 \\
& Brunt & $L_{n d c}$ & 1.019 & 0.997 & 19.347 \\
\hline \multirow{2}{*}{ All-sky } & Idso $L_{n d c}$ & $L_{n d}$ & 1.070 & 0.992 & 30.597 \\
& Brunt $L_{n d c}$ & $L_{n d}$ & 1.061 & 0.993 & 29.009 \\
\hline
\end{tabular}

3.7.2. Estimation of Downward Irradiance under All-Sky Conditions

Bilbao and De Miguel [42] proposed the following equation for the estimation of the daylight downward longwave irradiance under all-sky conditions $\left(L_{d n}\right)$ :

$$
L_{d n}=L_{d n c}\left[1+p\left(1-G / G_{c}\right)^{q}\right]
$$

where $L_{d n c}$ is the daylight downward longwave irradiance under clear-sky conditions (Equations (14) and (15)), $G / G_{c}$ is the ratio of the measured global solar horizontal irradiance to clear-sky global horizontal irradiance, and $p$ and $q$ are empirical coefficients. The above equation was selected because the experimental station proposed by the researches is an inland one with a latitude of about $41^{\circ} \mathrm{N}$ i.e., closed to our site of measurements. Clear-sky hourly horizontal irradiance was estimated from the following equation obtained from Haurwitz [43]:

$$
G_{c}=1098 * \cos \left(\theta_{z}\right) * \exp \left(-0.057 / \cos \left(\theta_{z}\right)\right)
$$

where $\theta_{z}$ is the solar zenith angle.

The calibration of the coefficients $p$ and $q$ of Equation (16) was based on the training data set (2013-2014) and its evaluation on the independent validation data set (2015). The final estimated local coefficients of $p$ and $q$ had the following values [9]:

$p=0.212$ and $q=1.608$ for the Idso model, and

$p=0.238$ and $q=1.613$ for the Brunt model.

Similar values of $p$ coefficients were obtained in Valladolid (Spain) [42], but the $q$ coefficients at Athalassa are almost twice higher than those in Spain. 
Using the current data set, and the coefficients reported earlier, the results of this exercise are presented in Table 6. As can be seen the slopes and the coefficients of determination are close to unity for both models for clear-sky conditions. On the other hand, both models showed slightly higher RMSE values than those obtained with clear conditions. Similar results were obtained by Bilbao and De Miguel [42] in Valladolid, Spain. The fitted line of the estimated versus the measured hourly daylight downward longwave irradiances under all-sky conditions, using the Idso's and Brunt's clear-sky models are shown in Figure 16. As seen, the data points are within the $95 \%$ prediction intervals. Additionally, the coefficients of determination are very close to each other, i.e., $71 \%$ and $72 \%$, respectively, for each model.
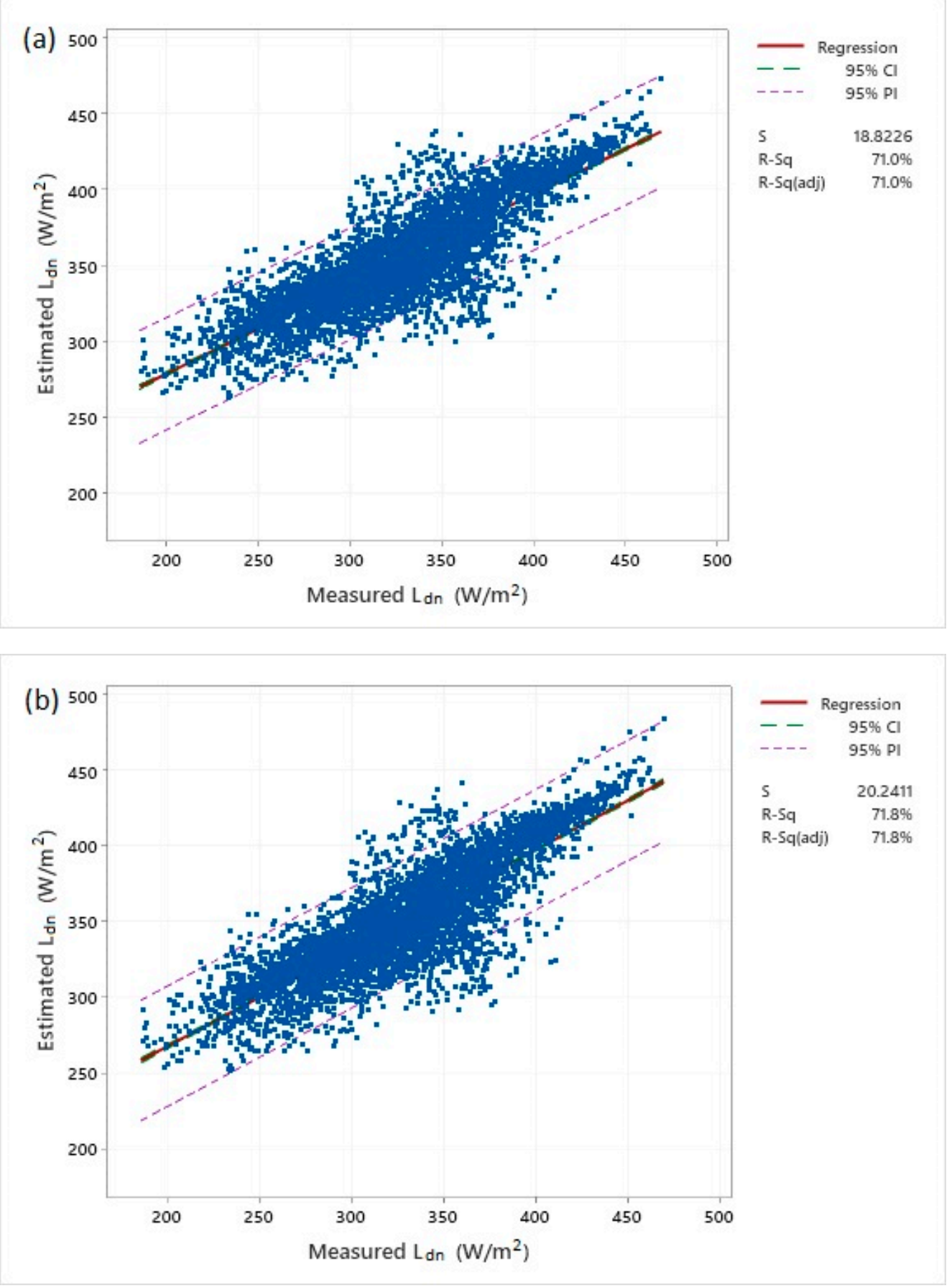

Figure 16. Comparison of measured and estimated hourly daylight downward longwave irradiances under all-sky conditions for the calibrated coefficients of (a) Idso's and (b) Brunt's models at Athalassa using the current dataset (2016-2017). 


\subsubsection{Parameterizing Longwave Downward Radiation for the All-Day Time Interval}

The previous section described the estimation of $L_{d n}$ during the daylight hours. The longwave radiation during daytime is necessary for the energy balance applications, while that during the nighttime is more favourable for the building passive cooling systems [4]. Chang and Zhang [7] have proposed an empirical equation to calculate $\left(L_{d n}\right)$ for the all-day, nighttime and daytime intervals. The proposed equation has the following form:

$$
L_{d n}=\sigma *\left(T_{a}\right)^{4} *\left(a * \ln \left(e / T_{a}\right)+b * R H+c\right)
$$

where $T_{a}$ is the air temperature in Kelvin, $e$ is the actual vapor pressure in $\mathrm{hPa}$ and $R H$ is the relative humidity in percentage; $a, b$, and $c$ are empirical coefficients. The proposed equation was selected because it is based on routine measurements of a meteorological station. For the all-day time interval, the original coefficients proposed by the authors have the following values: $a=0.08, b=0.0011$, and $c=1.029$. The coefficients of daytime and nighttime intervals showed almost similar values with those for the all-day time interval. Based on a training data set which covers the period of 2013-2015, the locally calibrated coefficients have been estimated giving the following values: $a=0.039, b=0.0007$ and $c=0.884$ [9]. The performance of the model showed a coefficient of determination of $\mathrm{R}^{2}=0.74$ and a RMSE $=22.95 \mathrm{~W} / \mathrm{m}^{2}$. Figure 17 shows the comparison of the estimated $L_{d n}$ for the all-day time interval and the measured values of $L_{d n}$ for the data set of the period 2016-2017. The $R^{2}$ is about 0.68 and the standard deviation of the residuals (S) is 21.869 (Figure 17). Almost all the data points are within the $95 \%$ prediction intervals.
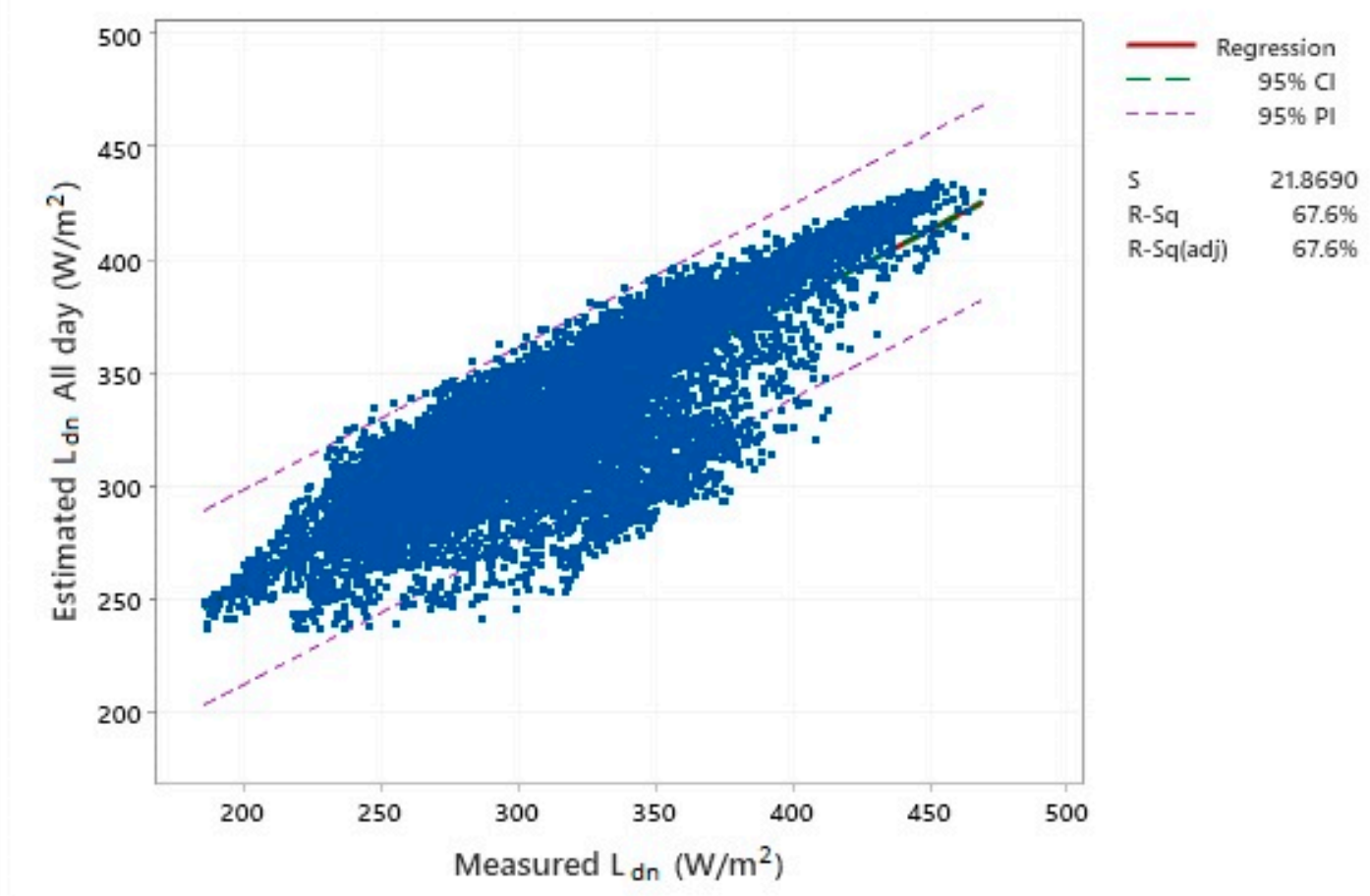

Figure 17. Comparison of estimated and measured $L_{d n}$ for the all day time interval for the data set of the period 2016-2017.

\subsection{Longwave Upward Radiation Parameterization}

The estimation of the upward emitted longwave irradiance from the ground surface is based on the Stefan-Boltzman equation:

$$
L_{u p}=\varepsilon_{\lg } * \sigma * T_{g}^{4}
$$


The longwave emittance of natural ground surfaces, $\varepsilon_{\lg }$, is typically around 0.96 [44]. $T_{g}$ is the ground surface temperature given in Kelvin. In a sunny weather, $T_{g}$ is higher than the screen air temperature $\left(T_{a}\right)$, but on clear winter nights it is below $T_{a}$. Figure 18a shows the relationship between the estimated longwave irradiance and the measured one using Equation (19). The graph shows a strong correlation between the two variables $\left(R^{2}=0.93\right)$, although a quadratic equation could give even higher correlation $\left(R^{2}=0.96\right)$.
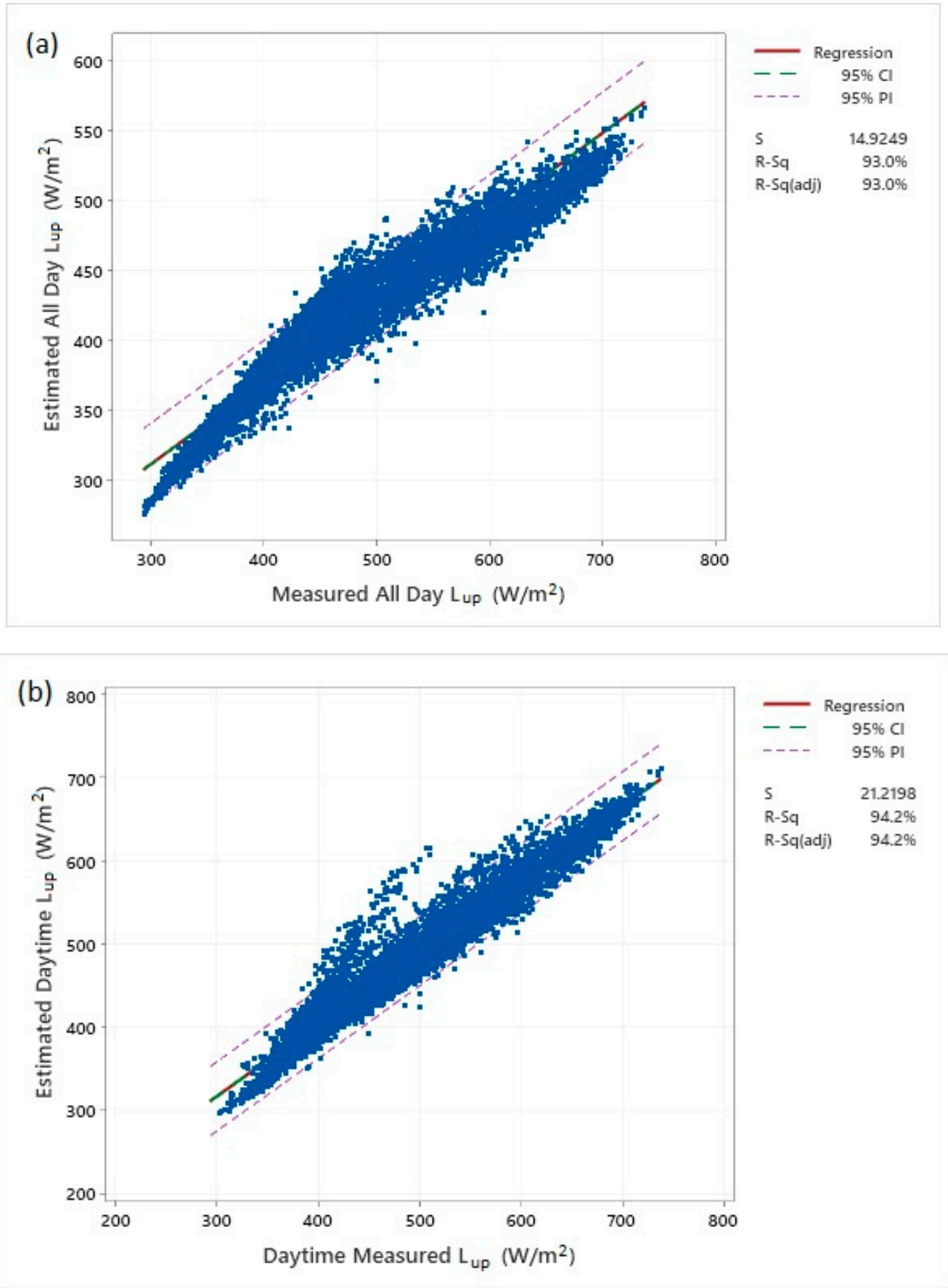

Figure 18. (a). Comparison of measured and estimated hourly upward longwave irradiances for the whole day using Equation (19). (b). Comparison of measured and estimated hourly daylight upward longwave irradiances for the calibrated Dognieux and Lemoine model at Athalassa using the data set 2016-2017. 
Dognieux and Lemoine [45] have also estimated daytime upward irradiance as a function of ground surface temperature, global solar radiation $(G)$ in $\mathrm{W} \mathrm{m}^{-2}$ and the ground albedo $\left(\rho_{g}\right)$ which is defined as the ratio of the Reflected solar irradiance to Global solar irradiance:

$$
L_{u p}=\sigma *\left[0.995 * T_{g}+0.023 *\left(1-\rho_{g}\right) * G\right]^{4}
$$

The above equation was used for the estimation of the daytime upward irradiance of the European Solar Radiation Atlas and therefore it was tested under Cyprus environmental conditions. The yearly average value of the ground albedo at Athalassa is 0.214 . In the current study, the hourly values of the albedo are used for the estimation of the upward longwave irradiance. The coefficients of Equation (20) were locally calibrated [9]. The original coefficients are very close to the calibrated ones. Figure $18 \mathrm{~b}$ shows the relationship between the estimated daytime longwave irradiance and the measured one. The figure indicates that there is also a strong correlation between the two variables $\left(R^{2}=0.942\right)$.

\subsection{Net Longwave Radiation}

The hourly net longwave irradiance, as indicated earlier, can be calculated from the respective difference of the downward and upward longwave irradiances. The hourly evolution of the calculated $R_{n l}$ irradiances are shown in Figure 6c, while Table 5 and Figure 12 show the monthly daily net longwave radiation. Equation (16) is applied to estimate downward irradiance values by using the coefficients obtained from the best performance Brunt model, whereas Equation (20) is used to estimate the upward longwave irradiance using the local calibrated coefficients. The scatterplot of the relationship between the estimated and calculated $R_{n l}$ is shown in Figure 19a. As indicated in the graph, the dispersions of the points are close to the fitted line with $\mathrm{R}^{2}=0.815$.

The net all-day downward longwave irradiance can be estimated from the difference of Equation (18) and the upward longwave irradiance estimated by Equation (19). The scatterplot of the relationship between the estimated and measured $R_{n l}$ is shown in Figure $19 \mathrm{~b}$. In this case, the coefficient of determination is $R^{2}=0.683$. The low coefficient of determination is attributed to the weak relationship obtained from the downward irradiance. Therefore, the prediction of $R_{n l}$ is better for the daytime rather the all-day interval.

Allen et al. [46] proposed an empirical equation to estimate the daily net longwave radiation $\left(R_{n l}\right)$ given by

$$
R_{n l}=\sigma_{S B} * T_{a}^{4} *\left(0.34-0.14 * e^{0.5}\right) *\left(1.35 * G / G_{c}-0.35\right)
$$

where $\sigma_{S B}=4.903 * 10^{-9} \mathrm{MJ} \mathrm{m}^{-2} \mathrm{~K}^{-4} \mathrm{~d}^{-1}$ (Stefan-Boltzman constant), $T_{a}$ is the mean daily air temperature in $\mathrm{K}, e$ is the mean daily vapor pressure in $\mathrm{kPa}, \mathrm{G}$ is the measured daily global solar radiation in $\mathrm{MJ} \mathrm{m}{ }^{-2}$, and $G_{c}$ is the calculated daily clear-sky radiation $\left(\mathrm{MJ} \mathrm{m}^{-2}\right)$. The above equation is used by WMO for the estimation of the reference evapotranspiration. Using all the available data, the above formula overestimates the net longwave radiation during the most months except the summer period (Figure 20). 

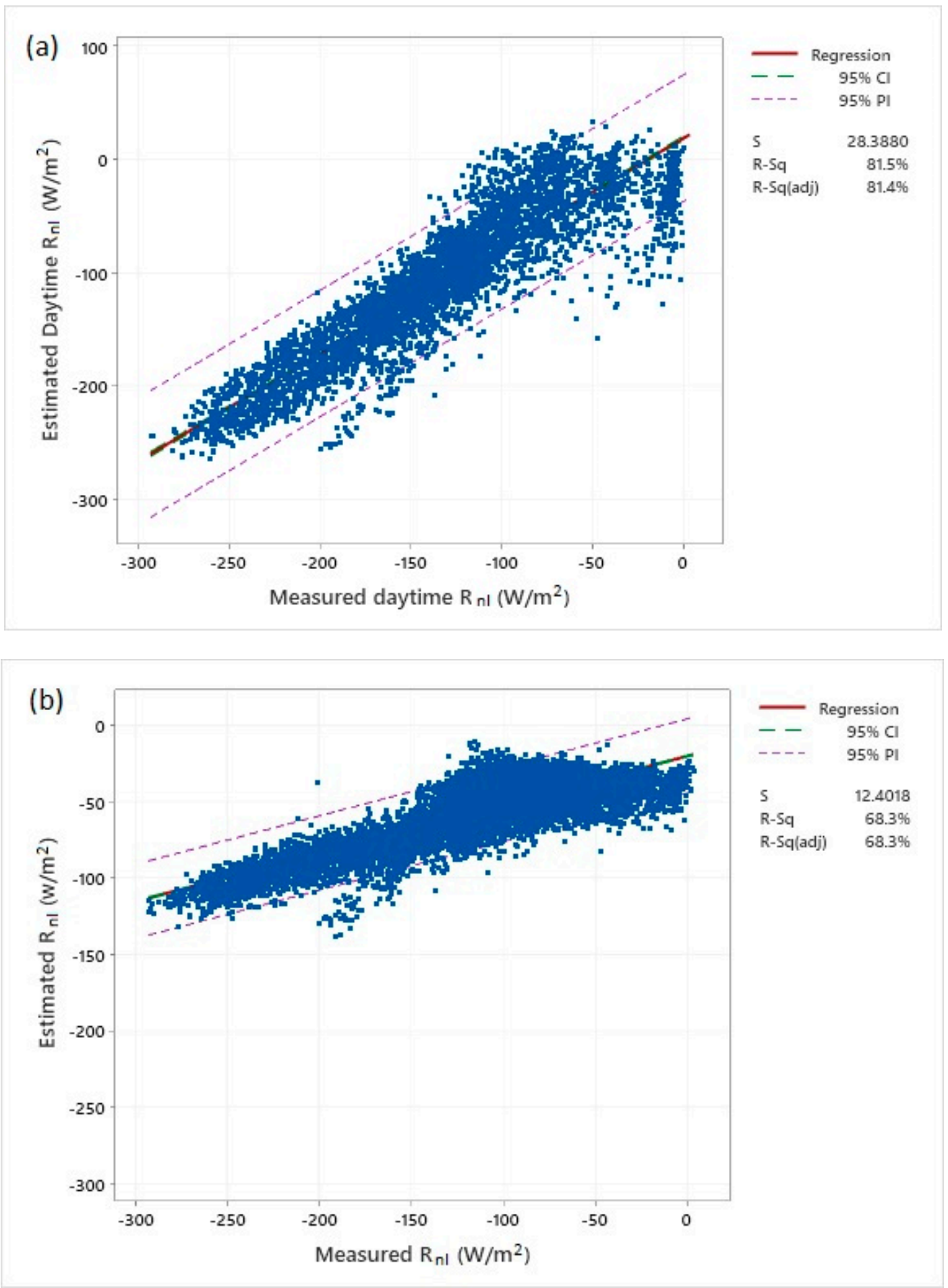

Figure 19. Comparison of measured and estimated hourly net longwave irradiances using the local calibrated coefficients at Athalassa for the period 2016-2017 (validation dataset), during (a) daytime and (b) all day intervals. 


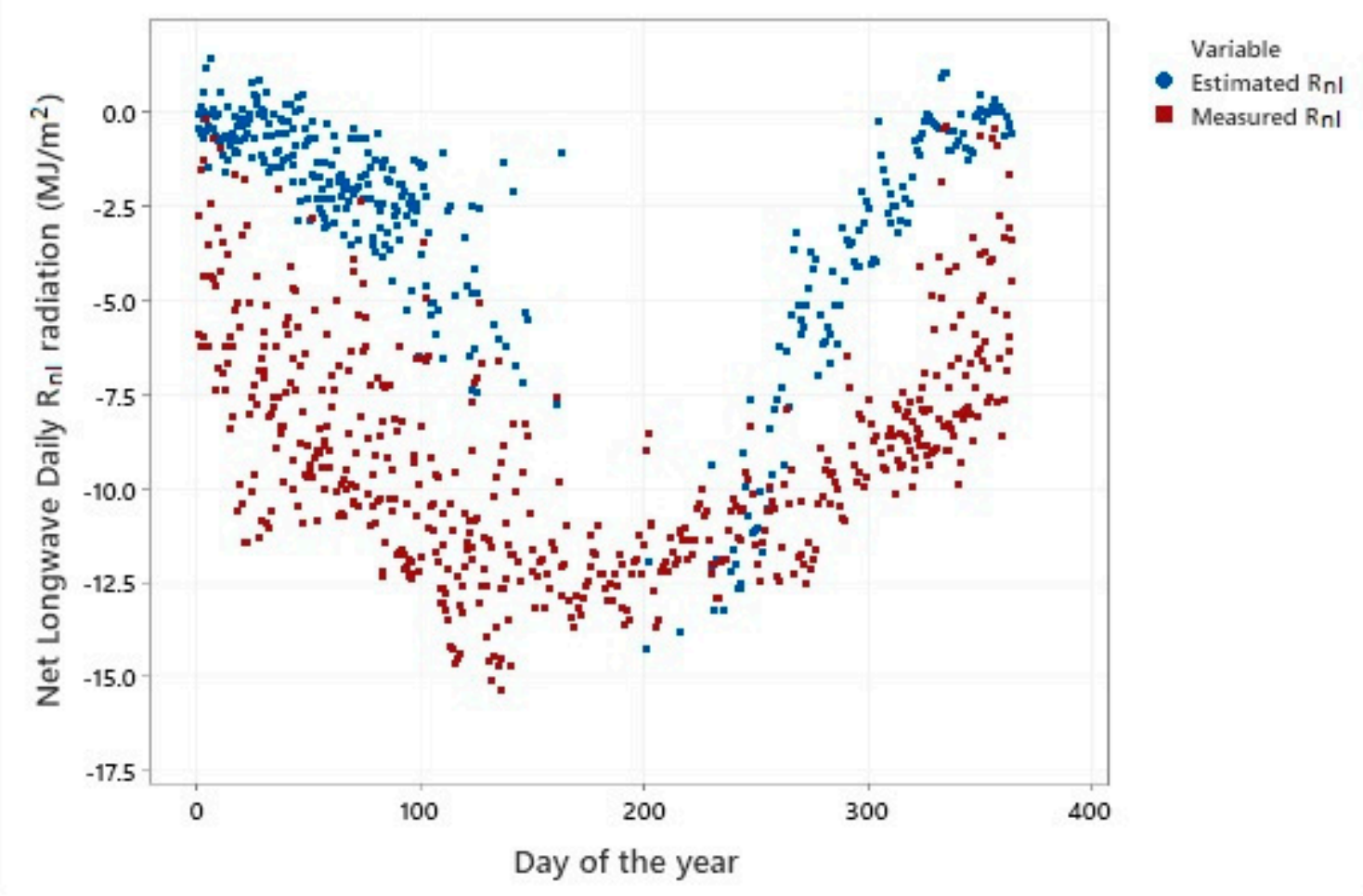

Figure 20. Comparison of the estimated Equation (21) and the measured daily net longwave radiation, at Athalassa.

\section{Conclusions}

Two years of hourly longwave downward and upward irradiance measurements for an inland location are used in the current study. Firstly, the data were undergone an extensive quality control process which was based on tests proposed by the BSRN group. These tests refer to physically possible limits, extremely rare, and climatological limits as well as comparison tests between the two longwave components and with air and ground surface temperatures. The upward irradiances showed slightly higher values than the climatological limits as suggested by the BSRN group. The slight excess (about $0.4 \%$ of data points) of the climatological limits of the upward irradiance could be attributed probably to the higher temperatures which prevail at this location. Therefore, all the upward longwave irradiance data were kept in the analysis. On the other hand, the downward irradiance showed unreasonable very low values during the period May-November 2017 and they did not pass the comparison criteria with air temperature. Therefore, 4128 hourly values of downward longwave irradiance were excluded from the statistical analysis due to instability of the pyrgeometer. Regarding to the time consistency test which assess the difference between successive measurements the available data set showed that the rate of changes between successive hours of the downward and upward irradiances are $<50 \mathrm{~W} \mathrm{~m}^{-2}$ and $<65 \mathrm{~W} \mathrm{~m}^{-2}$, respectively.

The second objective of this study refers to the statistical analysis of both hourly and daily values of the longwave radiation including their frequency distribution. As shown, a strong variability is observed during the winter and spring season. The maximum daily value of $L_{d n}$ is $35.2 \mathrm{MJ} \mathrm{m}^{-2}$ while the respective minimum value is $17.4 \mathrm{MJ} \mathrm{m}^{-2}$. The maximum daily value of $L_{u p}$ is $48.3 \mathrm{MJ} \mathrm{m}^{-2}$ and the minimum value is $26.3 \mathrm{MJ} \mathrm{m}^{-2}$. The annual mean daily downward longwave irradiation is $27.3 \mathrm{MJ} \mathrm{m}^{-2}$. On the other hand, the annual mean daily upward longwave irradiation is $37.8 \mathrm{MJ} \mathrm{m}^{-2}$. The higher air and ground surface temperatures are responsible for the higher values of upward longwave radiation at this site (inland), especially during the summer period at which $L_{u p}$ has the highest mean daily values from all the radiation components. As a result, the net longwave irradiation at Athalassa is always 
negative ranging from -5.9 to $-12.1 \mathrm{MJ} / \mathrm{m}^{2}$, which represents the radiative cooling potential. On the other hand, the net shortwave irradiation $\left(R_{n s}\right)$ ranges between 6.6 and $22.4 \mathrm{MJ} / \mathrm{m}^{2}$. Therefore, the net daily irradiation is positive ranging from 1.3 to $10.5 \mathrm{MJ} / \mathrm{m}^{2}$. The pattern of $R_{n}$ follows the same as the $R_{n l}$, i.e., higher values during the summer season. Regarding the frequency distribution of $L_{d n}$ irradiances the data showed that it follows a normal distribution function, while $L_{u p}$ follows an almost normal distribution but with a long positive tail. Since air temperatures are higher due to climate change process, we expect that both longwave components would be increased in the future.

A final objective was the estimation and evaluation of the performance of various models in estimating the downward and upward longwave irradiances under clear and allsky conditions during daytime or all the time of the day. For the case of clear sky conditions, the Idso's and Brunt's models were selected which showed the best performance among five models. For this purpose, local calibrated coefficients were estimated based on a training data set of the period 2013-2014 [9]. Implementing the data set for the period 2016-2017 showed that Brunt's model showed slightly better results than Idso's model, since RMSE was lower than that Idso's model.

The estimated longwave radiation during all-day time interval is based on air temperature and relative humidity measurements according to the model proposed by Chang and Zhang [7]. Based on a training data set which covers the period of 2013-2015, the local calibrated coefficients have the following values: $a=0.039, b=0.0007$, and $c=0.884$ [9]. The performance of the model showed a relatively strong correlation with a coefficient of determination of $\mathrm{R}^{2}=0.74$ and a $\mathrm{RMSE}=22.95 \mathrm{~W} / \mathrm{m}^{2}$.

The estimation of the upward longwave irradiance is more successful since it depends mainly on ground surface temperature and the properties of the soil and it can be estimated by the Stefan-Boltzman equation. The estimated and measured upward irradiances showed a strong correlation between the two variables $\left(R^{2}=0.93\right)$. A second model was tested for the estimation of the upward irradiance during daytime which was proposed by Dognieux and Lemoine [45]. The model again showed a strong correlation between the estimated and measured values $\left(\mathrm{R}^{2}=0.942\right)$.

The results of the study can be used for the estimation of the radiative cooling and the forecasting of the surface ground and air temperatures. Radiative cooling can reduce the energy consumption for building cooling in summer which is important in saving energy in very hot environments.

Author Contributions: Both authors contributed equally to this paper. All authors have read and agreed to the published version of the manuscript.

Funding: This research received no external funding.

Data Availability Statement: Data were obtained from the Cyprus Meteorological Department.

Conflicts of Interest: The authors declare no conflict of interest.

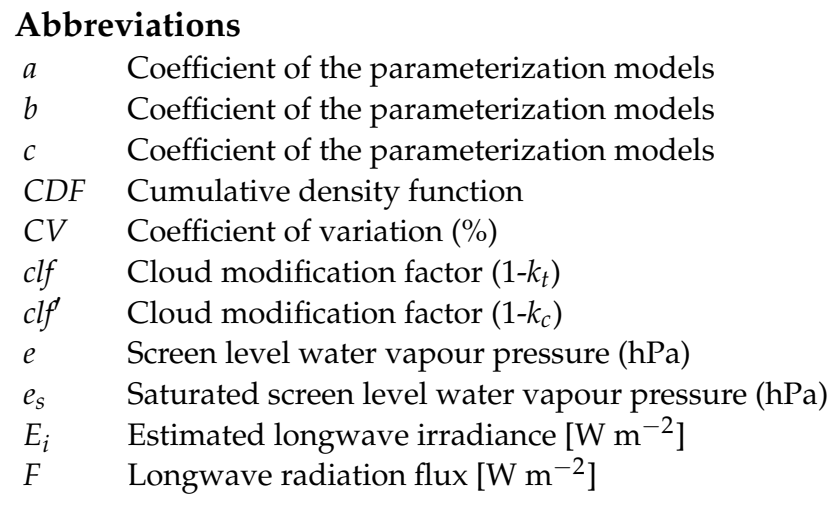




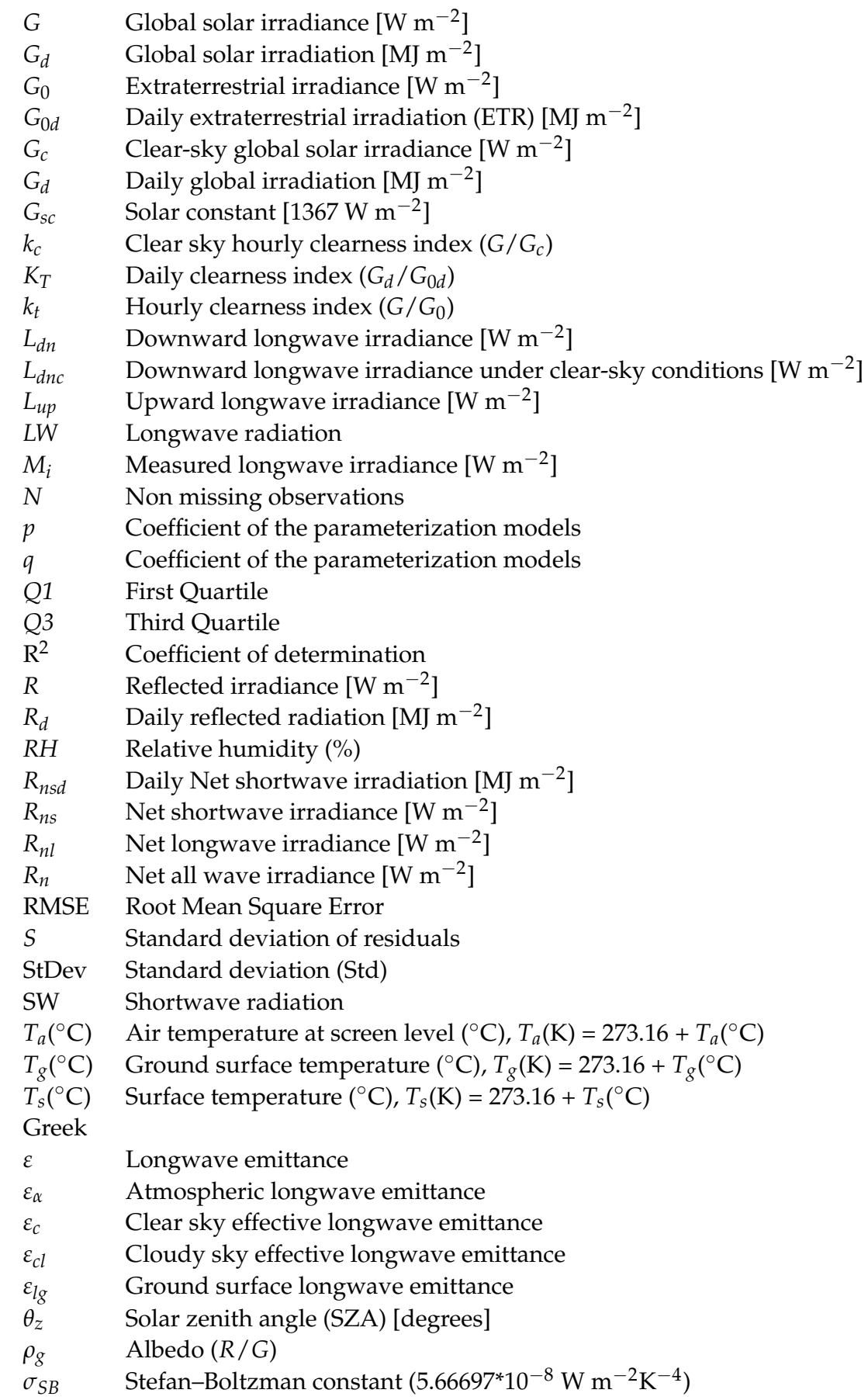

\section{References}

1. Monteith, J. Principles of Environmental Physics; Edward Arnold: London, UK, 1973.

2. Vall, S.; Castell, A. Radiative cooling as low-grade energy source: A literature review. Renew. Sustain. Energy Rev. 2017, 77, 803-820. [CrossRef]

3. Mateos, D.; Bilbao, J.; de Miguel, A.; Pérez-Burgos, A. Dependence of ultraviolet (erythemal and total) radiation and CMF values on total and low cloud covers in Central Spain. Atmos. Res. 2010, 98, 21-27. [CrossRef]

4. Li, M.; Jiang, Y.; Coimbra, C.F. On the determination of downward longwave irradiance under all-sky conditions. Sol. Energy 2017, 144, 40-48. [CrossRef]

5. Wild, M.; Ohmura, A.; Gilgen, H.; Morcrette, J.; Slingo, A. Evaluation of downward radiation in general circulation models. J. Climatol. 2001, 14, 3227-3229. [CrossRef]

6. Garcia, M. Simplified modelling of the nocturnal clear sky atmospheric radiation for environmental applications. Ecol. Model 2004, 180, 395-406. [CrossRef] 
7. Chang, K.; Zhang, Q. Modeling of downward longwave radiation and radiative cooling potential in China. J. Renew. Sustain. Energy 2019, 11, 066501. [CrossRef]

8. Stephens, G.L.; Wild, M.; Stackhouse, P.W., Jr.; L'Ecuyer, T.; Kato, S.; Henderson, D.S. The global character of the flux of downward longwave radiation. J. Clim. 2012, 25, 2329-2340. [CrossRef]

9. Pashiardis, S.; Kalogirou, S.A.; Pelengaris, A. Characteristics of longwave radiation through the statistical analysis of downward and upward longwave radiation and inter-comparison of two sites in Cyprus. J. Atmos. Sol. Terr. Phys. 2017, 164, 60-80. [CrossRef]

10. Marthews, T.R.; Malhi, Y.; Iwata, H. Calculating downward longwave radiation under clear and cloudy conditions over tropical lowland forest site: An evaluation of model schemes for hourly data. Theor. Appl. Climatol. 2011, 107, 461-477. [CrossRef]

11. Alados, I.; Foyo-Moreno, I.; Alados-Arboledas, L. Estimation of downwelling longwave irradiance under all-sky conditions. Int. J. Climatol. 2012, 32, 781-793. [CrossRef]

12. Crawford, T.M.; Duchon, C.E. An improved parameterization for estimating effective atmospheric emissivity for use in calculating daytime downwelling longwave radiation. J. Appl. Meteor. 1999, 38, 474-480. [CrossRef]

13. Prata, A. A new longwave formula for estimating downward clear sky radiation at the surface. Q. J. R. Meteorol. Soc. 1996, 122, 1127-1151. [CrossRef]

14. Choi, M.; Jacobs, J.M.; Kustas, W.P. Assessment of clear and cloudy sky parameterizations for daily downwelling longwave radiation over different land surfaces in Florida, USA. Geophys. Res. Lett. 2008, 35, L20402. [CrossRef]

15. Rizou, M.; Nnadi, F. Land use feedback on clear sky downward longwave radiation: A land use adapted model. Int. J. Climatol. 2007, 27, 1479-1496. [CrossRef]

16. Alados-Arboledas, L. Estimation of hourly values of downward atmospheric radiation under cloudless skies during day- and night-time conditions. Theor. Appl. Climatol. 1993, 48, 127-131. [CrossRef]

17. Goforth, M.A.; Gilchrist, G.W.; Sirianni, J.D. Cloud effects on thermal downwelling sky radiance. Proc. Spie 2002, $4710,203-213$.

18. Maghrabi, A.; Almutayri, M.M.; Aldosary, A.F.; Allehyani, B.I.; Aldakhil, A.A.; Aljarba, G.A.; Altilasi, M.I. The influence of atmospheric water content, temperature, and aerosol optical depth on downward longwave radiation in arid conditions. Theor. Appl. Climatol. 2019, 138, 1375-1394. [CrossRef]

19. Liu, M.; Zheng, X.; Zhang, J.; Xia, X. A revisiting of the parametrization of downward longwave radiation in summer over the Tibetan Plateau based on high-temporal-resolution measurements. Atmos. Chem. Phys. 2020, 20, 4415-4426. [CrossRef]

20. Choi, M. Parameterizing daytime downward longwave radiation in two Korean regional flux monitoring network sites. Hournal Hydrol. 2013, 476, 257-264. [CrossRef]

21. Carmona, F.; Rivas, R.; Caselles, V. Estimation of daytime downward longwave radiation under clear and cloudy skies conditions over sub-humid region. Theor. Appl. Climatol. 2014, 115, 281-295. [CrossRef]

22. Cheng, C.H.; Nnadi, F. Predicting downward longwave radiation for various land use in all-sky condition: Northeast Florida. Adv. Meteorol. 2014. [CrossRef]

23. Guo, Y.; Cheng, J.; Liang, S. Comprehensive assessment of parameterization methods for estimating clear-sky surface downward longwave radiation. Theor. Appl. Climatol. 2018, 135, 1045-1058. [CrossRef]

24. Jacovides, C.; Kaltsunides, N.; Hachioannou, L.; Stefanou, L. An assessment of the solar radiation climate of the Cyprus environment. Renew. Energy 1993, 3, 913-918. [CrossRef]

25. Jacovides, C.; Hachioannou, L.; Pashiardis, S.; Stefanou, L. On the Diffuse Fraction of daily and monthly Global Radiation for the island of Cyprus. Sol. Energy 1996, 56, 565-572. [CrossRef]

26. Jacovides, C.; Tymvios, F.; Giannourakos, G.; Pashiardis, S.; Stefanou, L. Recent measurements of broad-band Turbidity parameters in the island of Cyprus. Atmos. Environ. 1996, 30, 3391-3396. [CrossRef]

27. Jacovides, C.; Timvios, F.; Papaioannou, G.; Assimakopoulos, D.; Theofilou, C. Ratio of PAR to broadband solar radiation measured in Cyprus. Agric. For. Meteorol. 2004, 121, 135-140. [CrossRef]

28. Jacovides, C.; Assimakopoulos, V.; Tymvios, F.; Theophilou, K.; Assimakopoulos, D. Solar global UV (280-380 nm) radiation and its relationship with solar global radiation measured on the island of Cyprus. Energy 2006, 31, 2728-2738. [CrossRef]

29. Petrakis, M.; Kambezidis, C.; Lycoudis, S.; Adamopoulos, A.; Kasomenos, P.; Michaelides, I.; Kalogirou, S.; Rotitis, G.; Chrysis, L.; Hadjigianni, A. Generation of a 'typical meteorological year' for Nicosia, Cyprus. Renew. Energy 1998, 13, 381-388. [CrossRef]

30. Kalogirou, S.; Pashiardis, S.; Pashiardi, A. Statistical analysis and inter-comparison of the global solar radiation at two sites in Cyprus. Renew. Energy 2017, 101, 1102-1123. [CrossRef]

31. Pashiardis, S.; Kalogirou, S.A.; Pelengaris, A. Statistical analysis and characterization of solar energy utilization and intercomparison of solar radiation at two sites in Cyprus. Renew. Energy 2017, 190, 1138-1158. [CrossRef]

32. Long, C.N.; Shi, Y. An automated quality assessment and control algorithm for surface radiation measurements. Open Atmos. Sci. J. 2008, 2, 23-37. [CrossRef]

33. World Meteorological Organization (WMO). Guidelines on the Quality Control of Data from the World Radiometric Network; WCDP-3, WMO/TD-No. 258; WMO: Geneva, Swittzerland, 1987; p. 30.

34. Pashiardis, S.; Kalogirou, S.A. Quality control of solar shortwave and terrestrial longwave radiation for surface radiation measurements at two sites in Cyprus. Renew. Energy 2016, 96, 1015-1033. [CrossRef]

35. Lelieveld, J.; Hadjinicolaou, P.; Kostopoulou, E.; Chenoweth, J.; Maayar, M.; Giannakopoulos, C.; Hannides, C.; Lange, M.A.; Tenarhte, M.; Tyrlis, E.; et al. Climate change and impacts in the Eastern Mediterranean and the Middle East. Clim. Chang. 2012, 114, 667-687. [CrossRef] [PubMed] 
36. Lelieveld, J.; Proestos, Y.; Hadjinicolaou, P.; Tenarhte, M.; Tyrlis, E.; Zitis, G. Strongly increasing heat extremes in the Middle East and North Africa (MENA) in the 21st century. Clim. Chang. 2016, 137, 245-260. [CrossRef]

37. Kostopoulou, E.; Giannakopoulos, C.; Hatzaki, M.; Karali, A.; Hadjinicolaou, P.; Lelieveld, J.; Lange, M.A. Spatio-temporal patterns of recent and future climate extremes in Eastern Mediterranean and the Middle East region. Nat. Hazards Earth Syst. Sci. 2014, 114, 1565-1577. [CrossRef]

38. Estevez, J.; Gavilan, P.; Giraldez, J.V. Guidelines on validation procedures for meteorological data from automatic weather stations. J. Hydrol. 2011, 402, 144-154. [CrossRef]

39. Kudish, A.; Ianetz, A. Analysis of daily clearness index, global and beam radiation for Beer Sheva, Israel: Partition according to day type and statistical analysis. Energy Convers. Manag. 1996, 37, 405-416. [CrossRef]

40. Idso, S.B. A set of equations for full spectrum and 8-to $14 \mu \mathrm{m}$ and 10.5- to $12.5 \mu \mathrm{m}$ thermal radiation from cloudless skies. Water Resour. Res. 1981, 17, 295-304. [CrossRef]

41. Brunt, D. Notes on radiation in the atmosphere. Quart. J. R. Meteor. Soc. 1932, 58, 389-418. [CrossRef]

42. Bilbao, J.; De Miguel, A.H. Estimation of daylight downward longwave atmospheric irradiance under clear-sky and all-sky conditions. J. Appl. Meteorol. Climatol. 2006, 46, 878-889. [CrossRef]

43. Haurwitz, B. Insolation in relation to cloudiness and cloud density. J. Meteor. 1945, 2, 154-166. [CrossRef]

44. Scharmer, K.; Greif, J. The European Solar Radiation Atlas. Vol. 2: Database and Exploitation Software; Project No. JOU2-CT-94-0305; Presses des MINES: Paris, France, 2000.

45. Dognieux, R.; Lemoine, M. Valeurs Horaires Moyennes Mensuelles du Bilan Radiative et de ses Composantes a Uccle-Periode de Reference 1972-1982; Serie A 113; Institut royal météorologique de Belgique: Uccle, Belgium, 1984.

46. Allen, R.; Pereira, L.; Raes, D.; Smith, M. Crop Evapotranspiration-Guidelines for computing crop water requirements. Fao Irrig. Drain. Pap. 1998, 56, 300. 